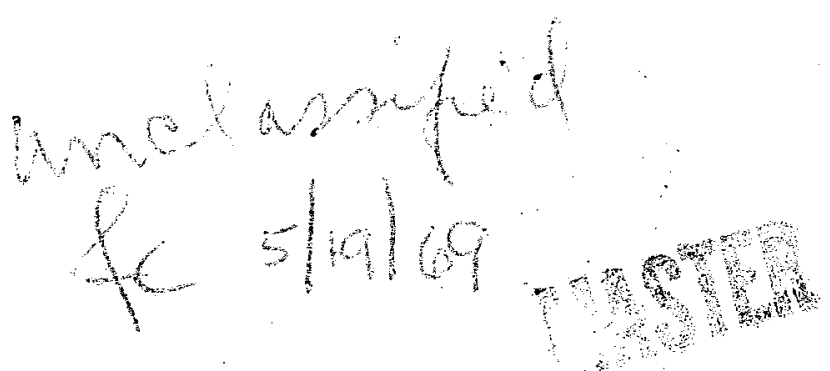

\title{
FABRICATION OF OXIDE NUCLEAR FUEL PELLETS
}

Malcolm R. Harvey

Alton R. Teter

Ronald L. Leggett

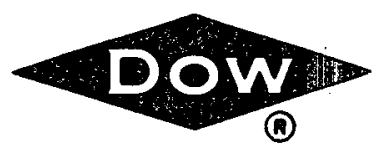

THE DOW CHEMICAL COMPANY

ROCKY FLATS DIVISION

P. O. BOX 888

GOLDEN, COLORADO 80401

U.S. ATOMIC ENERGY COMMISSION

CONTRACT AT(29-1)-1106 


\section{DISCLAIMER}

This report was prepared as an account of work sponsored by an agency of the United States Government. Neither the United States Government nor any agency Thereof, nor any of their employees, makes any warranty, express or implied, or assumes any legal liability or responsibility for the accuracy, completeness, or usefulness of any information, apparatus, product, or process disclosed, or represents that its use would not infringe privately owned rights. Reference herein to any specific commercial product, process, or service by trade name, trademark, manufacturer, or otherwise does not necessarily constitute or imply its endorsement, recommendation, or favoring by the United States Government or any agency thereof. The views and opinions of authors expressed herein do not necessarily state or reflect those of the United States Government or any agency thereof. 


\section{DISCLAIMER}

Portions of this document may be illegible in electronic image products. Images are produced from the best available original document. 
March 21, 1969

RFP-1255

UC-25 METALS, CERAMICS, AND MATERIALS

TID- 4500

FABRICATION OF OXIDE NUCLEAR FUEL PELLETS

Malcolm R. Harvey

Alton R. Teter

Ronald L. Leggett

\section{LEGAL NOTICE}

This report was prepared as an account of Government sponsored work. Neither the United States, nor the Commission, nor any person acting on behalf of the Commission:

A. Makes any warranty or representation, expressed or implied, with respect to the accuracy, completeness, or usefulness of the information contained in this report, or that the use of any information, apparatus, method, or process disclosed in this report may not infringe privately owned rights: or

B. Assumes any liablities with respect to the use of, or for damages resulting from the of any information, apparatus, method, or progess disclosed in this report.

$A B$ used in the above. "person acting on behalf of the Commission" includes any employee or contractor or the Commiselon, or employee dich employee or conides access to, any information purauant to his employment or contract

disseminates, or provides access to, any information pursuant to his employment or contract
with the Commission, or his employment with such contractor.

THE DOW CHEMICAL COMPANY ROCKY FLATS DIVISION

P. O. BOX 888

GOLDEN, COLORADO 80401

U. S. ATOMIC ENERGY COMMISSION

CONTRACT AT(29-1):-1106 
RFP-1255 


\section{CON TENTS}

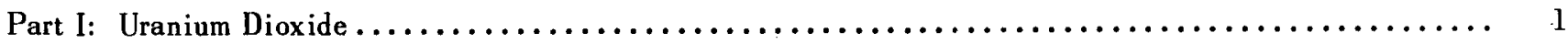

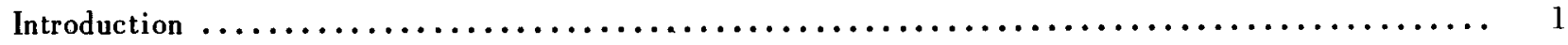

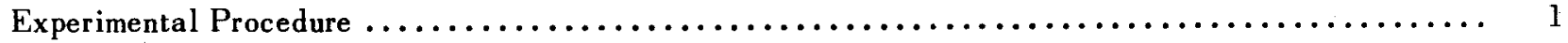

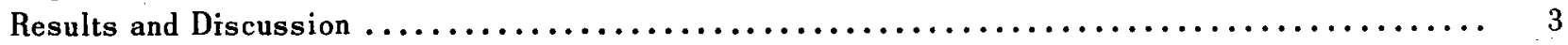

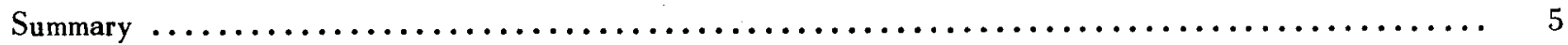

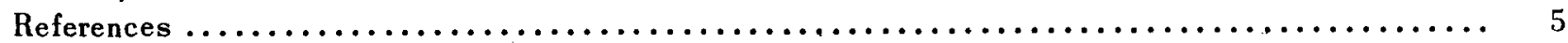

Appendix A: Literature Survey of Fabrication of $\mathrm{UO}_{2} \ldots \ldots \ldots \ldots \ldots \ldots \ldots$

Part II: Mixed Uranium-Plutonium Dioxides ............................... 23

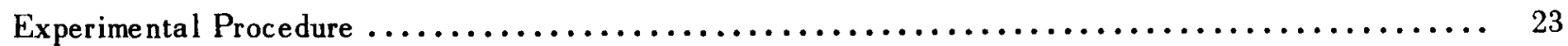

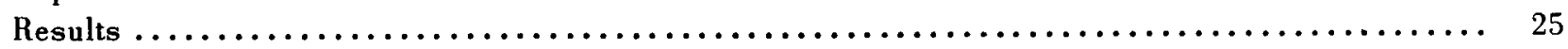

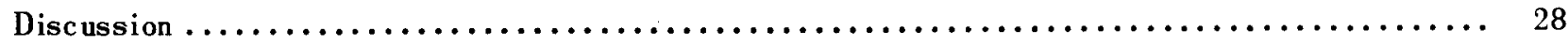

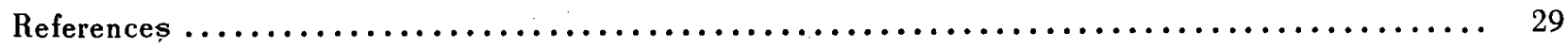

Appendix B: Literature Survey of Fabrication of Mixed Oxides. . . . . . . . . . . . . . . . 31

Appendix C: Plutonium Determination in Mixed Oxides by Calorimetric Measurements . . . . . . . . 39 
RFP-1255

\begin{abstract}
A BSTRACT
A small number of uranium dioxide and mixed uraniumplutonium dioxide fuel pellets were fabricated by the cold press and sinter technique. The diametral variations observed were less than $\pm 0.003 \mathrm{in}$. based on a nominal diameter of $0.345 \mathrm{in}$. The average hourglassing was $0.003 \mathrm{in}$. for a length to diameter ratio. of 1.5. It was concluded from this data and a literature survey that these variations could be maintained on a production basis and thus eliminate centerless grinding from the fabrication process.
\end{abstract}


PART I:

\section{URANIUM DIOXIDE}

Malcolm R. Harvey, Alton R. Teter, and Ronald L. Leggett

\section{INTRODUCTION}

A contract was received from Argonne National Laboratory to fabricate, by the cold press and sinter technique, a small number of $\mathrm{UO}_{2}$ and $(\mathrm{U}, \mathrm{Pu}) \mathrm{O}_{2}$ reactor fuel pellets (right circular cylinders). The statistical information obtained and reported here on $\mathrm{UO}_{2}$ was to be used in conjunction with a literature survey in writing a product specification for the fabrication of fuel elements for a zero power reactor. Exact diameters of the pellets were not specified, instead weights of material that could be introduced into a jacket with an inside diameter of $0.350 \mathrm{in}$. and a nominal length of 5.7 in. were fixed by A.N.L. This effectively required the diameters to be between 0.340 in. and $0.345 \mathrm{in}$. with a theoretical density of at least $92 \%$. The objective of this type of requirement was to allow some latitude on fired dimensions and densities with the idea of eliminating the centerless grinding step from the process.

Since there is a large amount of information available in the literature on the various fabrication parameters, e.g., binders, sintering times, temperatures, and atmospheres; emphasis was placed on determining variations in dimensions and densities. A problem with the literature however, which quickly became apparent, was that of duplication. In some cases the same information was reported four times, e.g., as quarterly reports, as a completion report, at a conference, and as a journal article. A representative list of the major references and abstracts dealing with important properties and fabrication of $\mathrm{UO}_{2}$ is attached as an appendix at the end of this report.

The main parameters effecting the sintering process will not be discussed here except for a short outline on what they are and how they apply to $\mathrm{UO}_{2}$.

The solid state sintering of crystalline solids is usually controlled by a diffusional mechanism with the reduction of the total surface area as the driving force. The stages of sintering, i.e., neck growth, reduction in porosity, and grain growth; are all diffusional in nature and are related in a complex manner to sintering time, temperature, and the stoichiometry. ${ }^{1}$ Uranium dioxide (oxide/metal ratio $=2.00$ ) normally needs to be fired to temperatures in excess of $1600^{\circ} \mathrm{C}$ for at least one hour in order to achieve densities greater than $90 \%$ of theoretical. ${ }^{2}$ Hyperstoichiometric $\mathrm{UO}_{2}+\mathrm{x}$ (where $x>0.05)$ can be sintered to the same densities at temperatures between $1100^{\circ}$ and $1300^{\circ} \mathrm{C} .^{2},{ }^{3}$ The difference in sintering temperatures is attributed to higher diffusion rates in hyperstoichiometric oxide.

The effect of changes in surface area on the densification of $\mathrm{UO}_{2}$ is the most dramatic but least characterized variable. Terms such as "active" or "sinterable grade" are used when ordering oxide that will sinter to high densities. This is because the determination of the particle size or surface area is only a rough indicator of sinterability. In general powders with a particle size less than $1.5 \mu$ or with a BET surface area greater than $2.5 \mathrm{~m}^{2} / \mathrm{g}$ will sinter to high densities. ${ }^{4}$ Poor sintering powders can usually be activated by milling or cycling through an oxidation-reduction process. ${ }^{3,5}$

\section{EXPERIMENTAL PROCEDURE}

A schematic for the fabrication of $\mathrm{UO}_{2}$ is shown in Figure 1. It is a composite taken from the literature and was chosen because of the available equipment and certain requirements imposed by A.N.L. Hyperstoichiometric $(\mathrm{O} / \mathrm{M}=2.06)$, depleted $\mathrm{UO}_{2}$ was purchased from Nuclear Materials and Equipment Corporation. The B.E.T. surface area was reported to be $4.24 \mathrm{~m}^{2} / \mathrm{g}$. A list of the reported impurities is given in Table $\mathrm{I}$.

Binder (1-wt \% Carbowax 4000) and a die lubricant (1-wt \% stearic acid) were added to the as-received powder in a $\mathrm{CCl}_{4}$ solution. These were needed because excessive losses, caused by laminations and chipping, were observed. These losses were attributed to insufficient green strength and poor die release. In addition, less hourglassing (maximum diameter-waist diameter) was observed when binder was added. The use of binders is not completely beneficial however, because they cause binder 


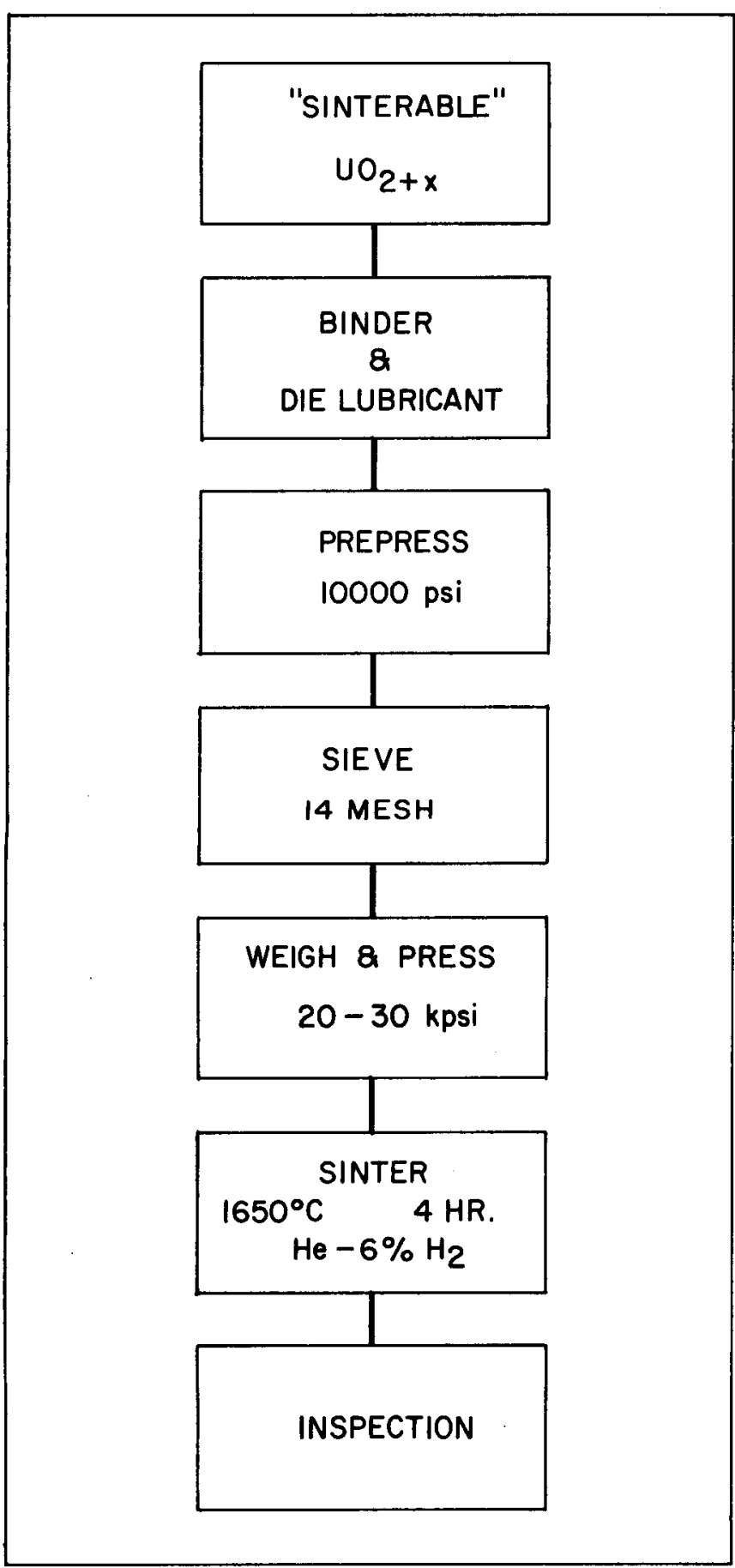

Figure 1. Schematic of fabrication process for $\mathrm{UO}_{2}$ pellets.

burnout problems, slightly reduced densities, ${ }^{6}$ and occasionally some carbide formation in the grain boundaries. $^{7}$

Pre-pressing was done in a isostatic press at $10,000 \mathrm{psi}$. The pre-pressed material was granulated by passing it through a 14 mesh screen. These two
Table 1. Chemical analysis of $\mathrm{UO}_{2}$.

\begin{tabular}{ccc} 
Element & Analysis (ppm) \\
\cline { 1 - 1 } $\mathrm{Al}$ & & $<20$ \\
$\mathrm{~B}$ & & $<0.5$ \\
$\mathrm{C}$ & & 20 \\
$\mathrm{Ca}$ & & $<25$ \\
$\mathrm{Cd}$ & & $<0.5$ \\
$\mathrm{Cl}$ & & $<10$ \\
$\mathrm{Co}$ & $<5$ \\
$\mathrm{Cu}$ & $<6$ \\
$\mathrm{Cr}$ & $<10$ \\
$\mathrm{~F}$ & $<134$ \\
$\mathrm{Fe}$ & $<20$ \\
$\mathrm{Mg}$ & $<10$ \\
$\mathrm{Mn}$ & $<10$ \\
$\mathrm{Mo}$ & $<10$
\end{tabular}

\begin{tabular}{ccc} 
Element & & Analysis (ppm) \\
\cline { 1 - 1 } $\mathrm{Be}$ & & $<10$ \\
$\mathrm{Zr}$ & & $<10$ \\
$\mathrm{Zn}$ & $<10$ \\
$\mathrm{~N}$ & 30 \\
$\mathrm{Ni}$ & $<10$ \\
$\mathrm{~Pb}$ & 2 \\
$\mathrm{~S}_{\mathrm{i}}$ & & $<50$ \\
$\mathrm{Ti}$ & 20 \\
$\mathrm{~V}$ & $<1$ \\
$\mathbb{W}$ & & $<25$ \\
Dy + Eu + Gd $+\mathrm{Sm}$ & & $<0.07$ \\
$\% \mathrm{U}-235$ & & 0.218
\end{tabular}

steps are very important because they impart flowability to the powder and also reduce hourglassing and shrinkage. Close height control was maintained by individually weighing each pressing charge to \pm 0.05 grams. Based on experiments here and data reported in the literature ${ }^{8}$ a length-to-diameter ratio (L/D) of 1.5 was used. (Excessive hourglassing and insufficient green strength were observed with ratios greater than 1.5.) The powder was pressed in a modified double acting Carver Laboratory press. Pressing pressures were investigated between 18,000 and $50,000 \mathrm{psi}$. Although much higher pressures have been reported elsewhere, they were not used here because the tops of many pellets spalled off as the pressures were increased to 50,000 psi.

Laminations produced by pellet expansion during ejection were eliminated by grinding a slight taper $(1 / 2 \circ$.by $1 / 4-$ in. deep $)$ into the die wall. Pressures lower than 18,000 psi were not used because pellet ejection pressure was approximately $18,000 \mathrm{psi}$. After establishing the shrinkage versus pressure relationship a range of 20,000 to 30,000 psi was chosen for fabrication of the pellets. The green densities obtained using these pressures varied from 45 to $50 \%$ of theoretical. Sintering was done in alumina saggers using a coarse (8 mesh) alumina bedding grain. The "high temperature" process was used to sinter the $\mathrm{UO}_{2}$ pellets because stoichiometric oxides were required by A.N.L. (Based on available diffusion data ${ }^{9}$ it is doubtful that full reduction of a pellet can be achieved by any of the "low temperature" two stage sintering processes.) The nominal firing temperature and time used were $1650^{\circ} \mathrm{C}$ for 4 hours. Preliminary runs were made in a dry (dew point $-175^{\circ} \mathrm{F}$ ) $94 \%$ helium $-6 \%$ hydrogen atmosphere, whereas the two production runs were made in dry, pure hydrogen. Firing rates depended to some extent on the type 
Table Il. Data obtained from $\mathrm{UO}_{2}$ pellets sintered in a $94 \% \mathrm{He}-6 \% \mathrm{H}_{2}$ atmosphere.*

\begin{tabular}{|c|c|c|c|c|c|c|c|c|c|}
\hline $\begin{array}{c}\text { Sintering } \\
\text { Test }\end{array}$ & $\begin{array}{c}\text { Sintering } \\
\text { Temp. } \\
\left({ }^{\circ} \mathrm{C}\right)\end{array}$ & $\begin{array}{c}\text { Pre- } \\
\text { Pressing } \\
\text { Pressure } \\
\text { (psi) }\end{array}$ & $\begin{array}{c}\text { Pressing } \\
\text { Pressure } \\
\text { (psi) }\end{array}$ & $\begin{array}{l}\text { L to D } \\
\text { Ratio }\end{array}$ & $\begin{array}{l}\text { Distortion } \\
\text { (in.) }\end{array}$ & $\begin{array}{l}\text { Hour- } \\
\text { glassing } \\
\text { (in.) }\end{array}$ & $\begin{array}{l}\text { Percent } \\
\text { Shrinkage }\end{array}$ & $\begin{array}{l}\text { Theor. } \\
\text { Density } \\
(\%)\end{array}$ & Appearance \\
\hline \multirow{2}{*}{$\mathrm{A}_{2}^{1}$} & $1650-4 \mathrm{hr}$. & 10000 & 19,600 & 1.00 & 0.0088 & 0.0095 & 19.0 & 91.3 & Distortion \\
\hline & $1650-4 \mathrm{hr}$ & 10000 & 50,000 & 1.50 & 0.0069 & 0.0110 & 15.9 & 91.7 & Distortion \\
\hline \multirow{3}{*}{$\begin{array}{r}1 \\
\text { B } 2 \\
3\end{array}$} & $1650-4 \mathrm{hr}$. & 10000 & 25,000 & 1.60 & 0.0004 & 0.0050 & 19.3 & 93.0 & Excellent \\
\hline & $1650-4 \mathrm{hr}$. & 10000 & 30,000 & 1.60 & 0.0004 & 0.0048 & 18.8 & 92.9 & Excellent \\
\hline & $1650-4 \mathrm{hr}$. & 10000 & 35,000 & 1.60 & 0.0003 & 0.0043 & 18.0 & 92.9 & Excellent \\
\hline \multirow{4}{*}{$\begin{array}{r}1 \\
\mathrm{C} \\
2 \\
3 \\
4\end{array}$} & $1675-4 \mathrm{hr}$. & 10000 & 18,000 & 1.50 & 0.0002 & 0.0027 & 20.7 & 95.2 & Pock marks \\
\hline & $1675-4 \mathrm{hr}$ & 10000 & 24,500 & 1.50 & 0.0004 & 0.0033 & 19.8 & 94.8 & Pock marks \\
\hline & 1675-4 hr. & 10000 & 32,400 & 1.50 & 0.0003 & 0.0032 & 18.8 & 94.8 & Pock marks \\
\hline & $1675-4 \mathrm{hr}$. & 10000 & 39,600 & 1.50 & 0.0002 & 0.0031 & 17.9 & 95.0 & Pock marks \\
\hline
\end{tabular}

* All data is the average of $4-5$ pellets.

of furnace being used except that the rates were always held to less than $100^{\circ} \mathrm{C} / \mathrm{hr}$ to $500^{\circ} \mathrm{C}$ and above $1200^{\circ} \mathrm{C}$. The preliminary runs indicated that good dimensional control could not be maintained with rates higher than $100^{\circ} \mathrm{C} / \mathrm{hr}$ above $1200^{\circ} \mathrm{C}$. Higher rates produced pellets with an appreciable amount of distortion (bottom diameter-top diameter).

A visual inspection of all pellets was made for blow holes, laminations, and chips. Dimensions were obtained on all samples with a blade micrometer. Measurements were taken from the top, waist, and bottom diameters of the pellets. Immersion densities, using kerosene and vacuum, were determined on a random sampling from each sagger.

\section{RESULTS AND DISCUSSION}

Table II lists some of the data obtained from the preliminary runs which were used to establish shrinkage as a function of pressing pressure. Other variables such as firing rates, amounts of binders and lubricants, pre-pressing and L/D ratio, were examined at this time. It appears that there is no effect from forming pressure on the sintered density. This means that the time at sintering temperature is sufficient to eliminate the pressing as a densification variable. The distortion in series $\mathrm{A}$ is assumed to be caused by excessively high rates of temperature rise discussed previously. The rate of rise for series A was in excess of $200^{\circ} / \mathrm{hr}$ while series $\mathrm{B}$ and $\mathrm{C}$ were held to $100^{\circ} \mathrm{C} / \mathrm{hr}$ above $1200^{\circ} \mathrm{C}$. (The hourglassing in series $\mathrm{B}$ was slightly greater than in series $\mathrm{C}$ because of the greater $\mathrm{L} / \mathrm{D}$ ratio). The data from Table II also indicate that the density is effected by the firing rate. Figure 2 clearly shows that the cross-section of a distorted pellet has

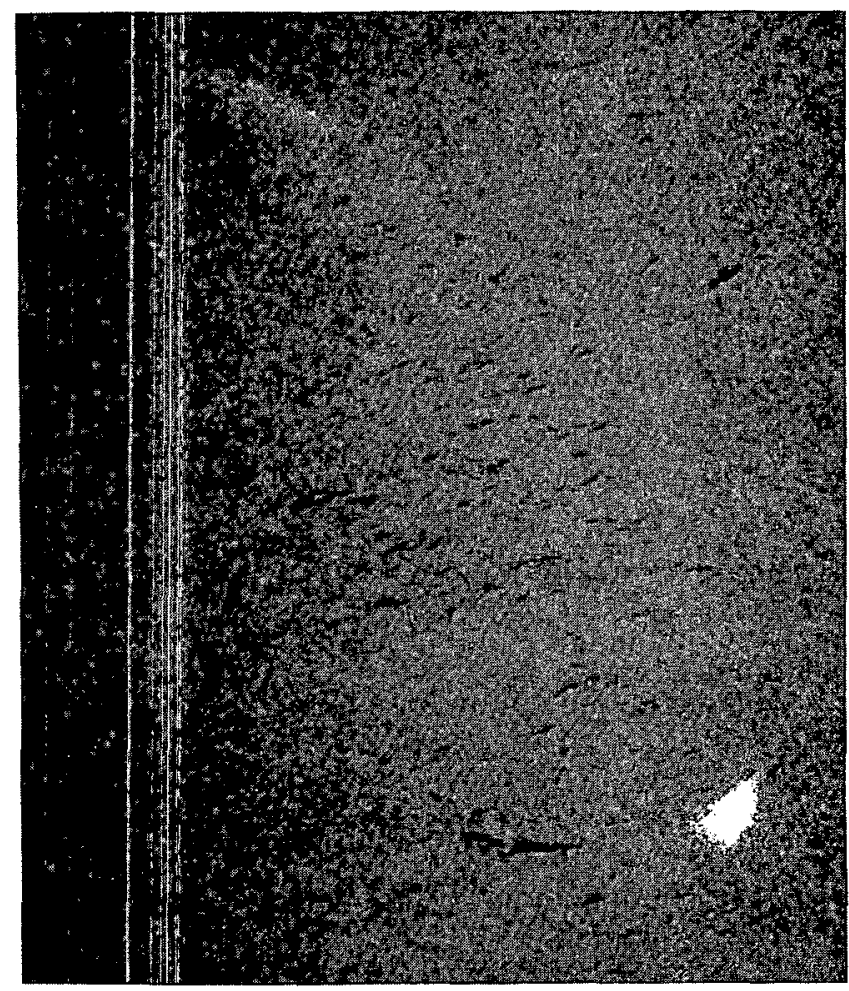

Figure 2. Cross-section of $\mathrm{UO}_{2}$ pellet showing high porosity at base caused by high firing rate between 1200 and $1650^{\circ} \mathrm{C}$.

$10 \mathrm{X}$

failed to densify properly. This low density area was always at the base of the pellet which implies a gas-solid surface reaction controlling the shrinkage. This was further confirmed when the distortion was decreased by drilling holes in the saggers and using bedding grain under the pellets. It must be emphasized however, that the distortion was completely eliminated only when the firing rate above 
RFP-1255

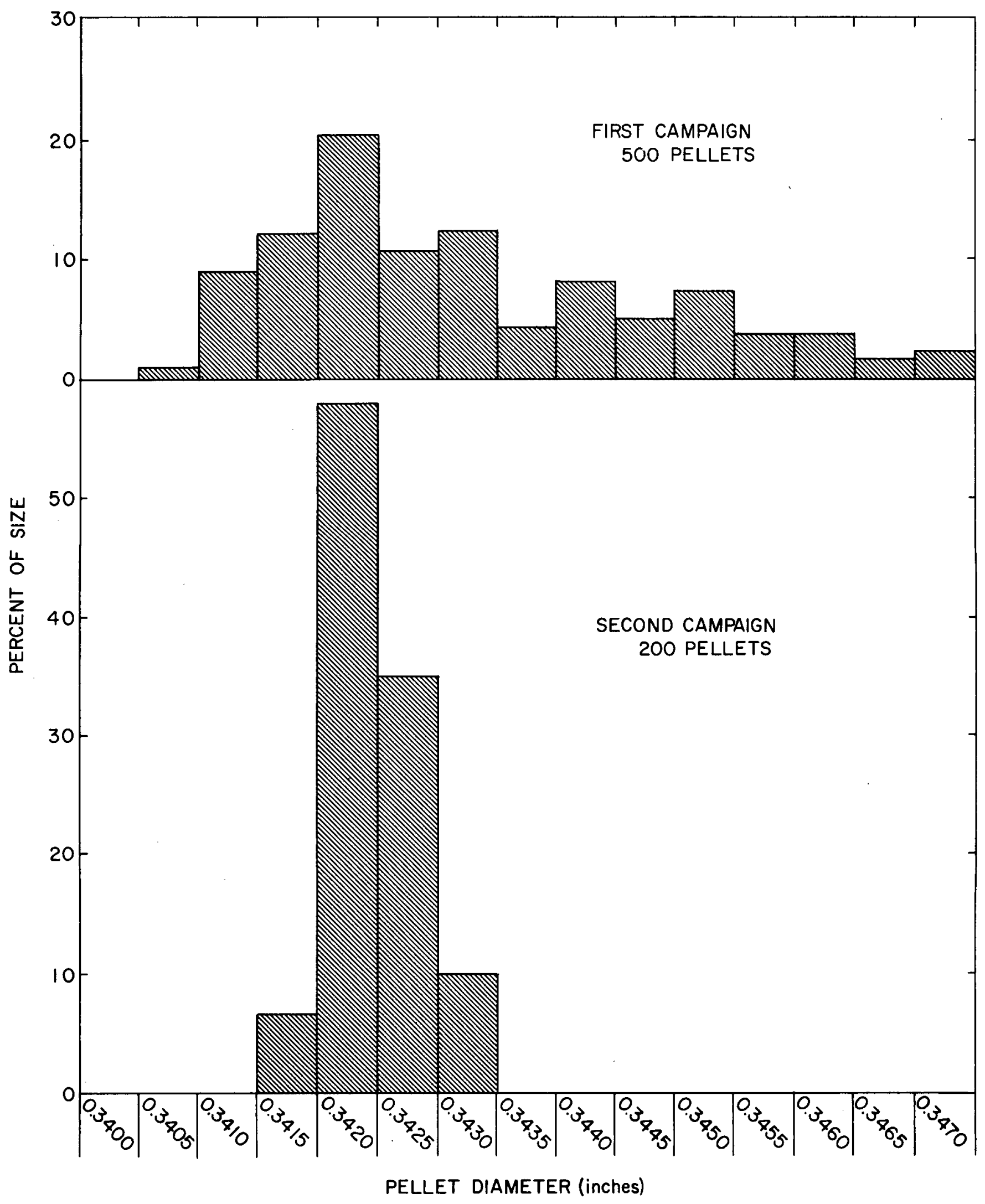

Figure 3. Histogram of $\mathrm{UO}_{2}$ pellet diameters. 
$1200^{\circ} \mathrm{C}$ was held below $100^{\circ} \mathrm{C} /$ hour. Series C showed the effect of alumina bedding grain sticking to the pellet surface. This is assumed to be due to the slight increase in temperature for this series.

The first production run of 500 pellets (lst campaign) was sintered at $1650^{\circ} \mathrm{C}$ for 4 hours in pure hydrogen. Approximately $90 \%$ of the pellets fell in the density range of 93-94\% of thearetical (Table III). The failure of the remaining pellets to densify (or shrink) was caused by a poor temperature profile in the furnace. There were some additional losses caused by the alumina bedding grain imbedding itself into the pellets.

Table III. Data from $500 \mathrm{UO}_{2}$ pellets fired at $1650^{\circ} \mathrm{C}$ for 4 hours (first campaign).

\begin{tabular}{|c|c|c|c|c|c|}
\hline $\begin{array}{l}\text { Sagger } \\
\text { No. } \\
\end{array}$ & $\begin{array}{l}\text { Hourglassing* } \\
\quad \text { (in.) } \\
\end{array}$ & $\begin{array}{l}\text { Distortion* } \\
\text { (in.) } \\
\end{array}$ & $\begin{array}{l}\text { Shrinkage* } \\
(\%) \\
\end{array}$ & $\begin{array}{c}\text { Theo. } \\
\text { Dens.** } \\
(\%)\end{array}$ & $\begin{array}{c}\text { Loss } \\
\text { Per } \\
\text { Sagger } \\
\end{array}$ \\
\hline A- 1 & 0.0042 & 0.0011 & 18.31 & 91.73 & 12 \\
\hline 2 & 0.0041 & 0.0011 & 17.93 & 91.62 & 19 \\
\hline 3 & 0.0043 & 0.0010 & 18.03 & 91.50 & 16 \\
\hline 4 & 0.0033 & 0.0006 & 18.19 & 91.81 & 9 \\
\hline $\mathrm{B}_{-1}$ & 0.0034 & 0.0007 & 18.22 & 94.04 & 3 \\
\hline 2 & 0.0033 & 0.0006 & 18.22 & 93.90 & 6 \\
\hline 3 & 0.0031 & 0.0007 & 18.46 & 93.97 & 1 \\
\hline 4 & 0.0026 & 0.0004 & 18.74 & 93.95 & 3 \\
\hline$C_{-1}$ & 0.0031 & 0.0005 & 18.86 & 93.47 & 6 \\
\hline 2 & 0.0027 & 0.0003 & 18.93 & 93.74 & 6 \\
\hline 3 & 0.0028 & 0.0004 & 18.91 & 93.77 & 1 \\
\hline 4 & 0.0029 & 0.0005 & 18.88 & 93.58 & 5 \\
\hline D- 1 & 0.0033 & 0.0007 & 18.76 & 93.45 & 6 \\
\hline 2 & 0.0034 & 0.0007 & 18.76 & 93.47 & 3 \\
\hline 3 & 0.0031 & 0.0005 & 18.81 & 93.74 & 2 \\
\hline 4 & 0.0028 & 0.0005 & 18.86 & 93.57 & 3 \\
\hline $\mathbf{E}_{-1}$ & 0.0034 & 0.0005 & 18.81 & 93.88 & 4 \\
\hline 2 & 0.0032 & 0.0006 & 18.79 & 93.52 & 3 \\
\hline 3 & 0.0033 & 0.0010 & 18.60 & 92.95 & 7 \\
\hline 4 & 0.0033 & 0.0008 & 18.57 & 92.77 & 6 \\
\hline
\end{tabular}

* Averaged from all pellets in sagger.

** Average of five pellets from each sagger of twenty-five. Overall average density was 93.62 . Standard deviation was 0.41 .

The second production run (2nd campaign) of 200 pellets was sintered at $1635^{\circ} \mathrm{C}$ to try and eliminate the effect of the alumina grain. Losses as a result of surface imperfections were virtually eliminated; however, there was a slight decrease in density (Table IV).

The diametral variations from both campaigns are shown in Figure 3. The large spread in the first campaign reflects the reduced shrinkage caused
Table IV. Data from $200 \mathrm{UO}_{2}$ pellets fired at $1635^{\circ} \mathrm{C}$ for 4 hours (second campaign).

\begin{tabular}{|c|c|c|c|c|c|}
\hline $\begin{array}{l}\text { Sagger } \\
\text { No. }\end{array}$ & $\begin{array}{l}\text { Hourglassing* } \\
\text { (in.) }\end{array}$ & $\begin{array}{l}\text { Distortion* } \\
\quad \text { (in.) }\end{array}$ & $\begin{array}{l}\text { Shrinkage* } \\
(\%)\end{array}$ & $\begin{array}{c}\text { Theo. } \\
\text { Dens.** } \\
\text { (\%) }\end{array}$ & $\begin{array}{c}\text { Loss } \\
\text { Per } \\
\text { Sagger }\end{array}$ \\
\hline A-1 & 0.0027 & 0.0003 & 18.69 & 92.07 & 1 \\
\hline 2 & 0.0023 & 0.0002 & 18.79 & 92.42 & 1 \\
\hline 3 & 0.0027 & 0.0003 & 18.76 & 92.42 & 1 \\
\hline B- 1 & 0.0027 & 0.0003 & 18.71 & 92.45 & 0 \\
\hline 2 & 0.0026 & 0.0003 & 18.74 & 92.29 & 0 \\
\hline 3 & 0.0027 & 0.0003 & 18.79 & 92.44 & 0 \\
\hline C- 1 & 0.0030 & 0.0003 & 18.76 & 92.28 & 1 \\
\hline 2 & 0.0027 & 0.0003 & 18.79 & 92.20 & 1 \\
\hline 3 & 0.0023 & 0.0004 & 18.71 & 92.63 & 1 \\
\hline D. 1 & 0.0022 & 0.0003 & 18.76 & 92.73 & 1 \\
\hline 2 & 0.0026 & 0.0004 & 18.76 & 92.90 & 1 \\
\hline 3 & 0.0028 & 0.0004 & 18.76 & 92.65 & 0 \\
\hline$X-1$ & 0.0025 & 0.0003 & 18.76 & 93.26 & 2 \\
\hline
\end{tabular}

* Averaged from pellets in sagger.

** Average of four pellets in sagger of sixteen. Overall average density was 92.49. Standard deviation was 0.40 .

by the cold zone. The second campaign shows the variations that might be observed if very tight process control is maintained. Histograms of the variations in waist diameter and the heights of the pellets from the second campaign are shown in Figures 4 and 5 . Comparing the histograms in Figures 3 and 4 indicates the average hourglassing for the $\mathrm{UO}_{2}$ pellets was approximately 3 mils.

\section{SUMMARY}

Assuming the results reported here can be scaled up, it seems apparent that reactor fuel pellets can easily be fabricated on a production basis to specifications which allow less than \pm 0.003 in. diametral variation. With only moderately active powders, densities greater than $93 \%$ of theoretical can be achieved with less than $\pm 1 \%$ absolute variation.

\section{REFERENCES}

1. Progress in Ceramic Science, Chapter 4, edited by J. E. Burke, MacMillan Company, New York, 1963.

2. J. Williams, E. Barnes, R. Scott and A. Hall, "Sintering of Uranium Oxides of Composition $\mathrm{UO}_{2}$ to $\mathrm{U}_{3} \mathrm{O}_{8}$ in Various Atmospheres," J. Nucl. Matls., l (1959) 28-38. 
RFP-1255

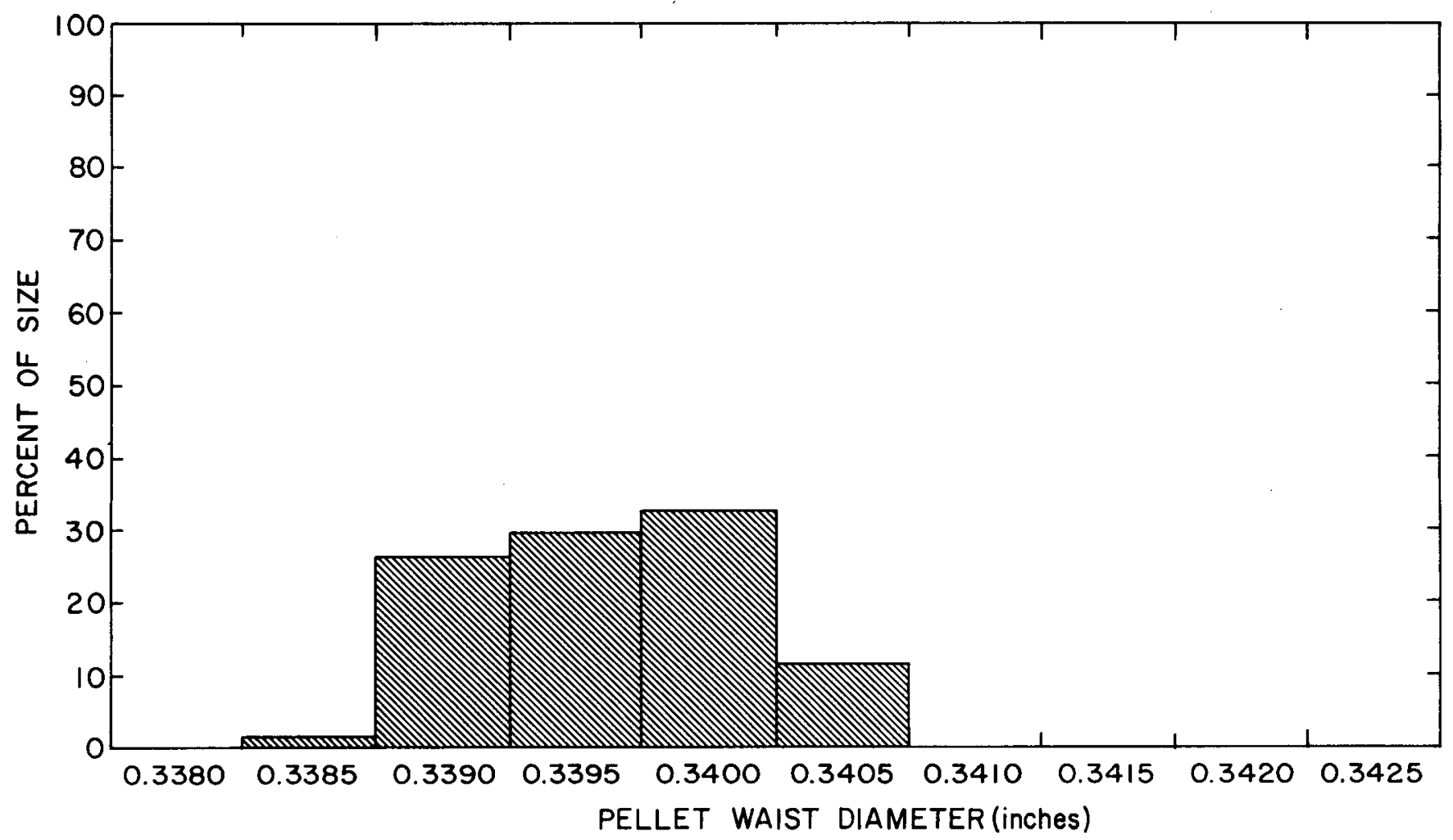

Figure 4. Histogram of variation in waist diameter of second campaign of $\mathrm{UO}_{2}$ pellets.

Figure 5. Histogram of variation in pellet height for second campaign of $\mathrm{UO}_{2}$ pellets.

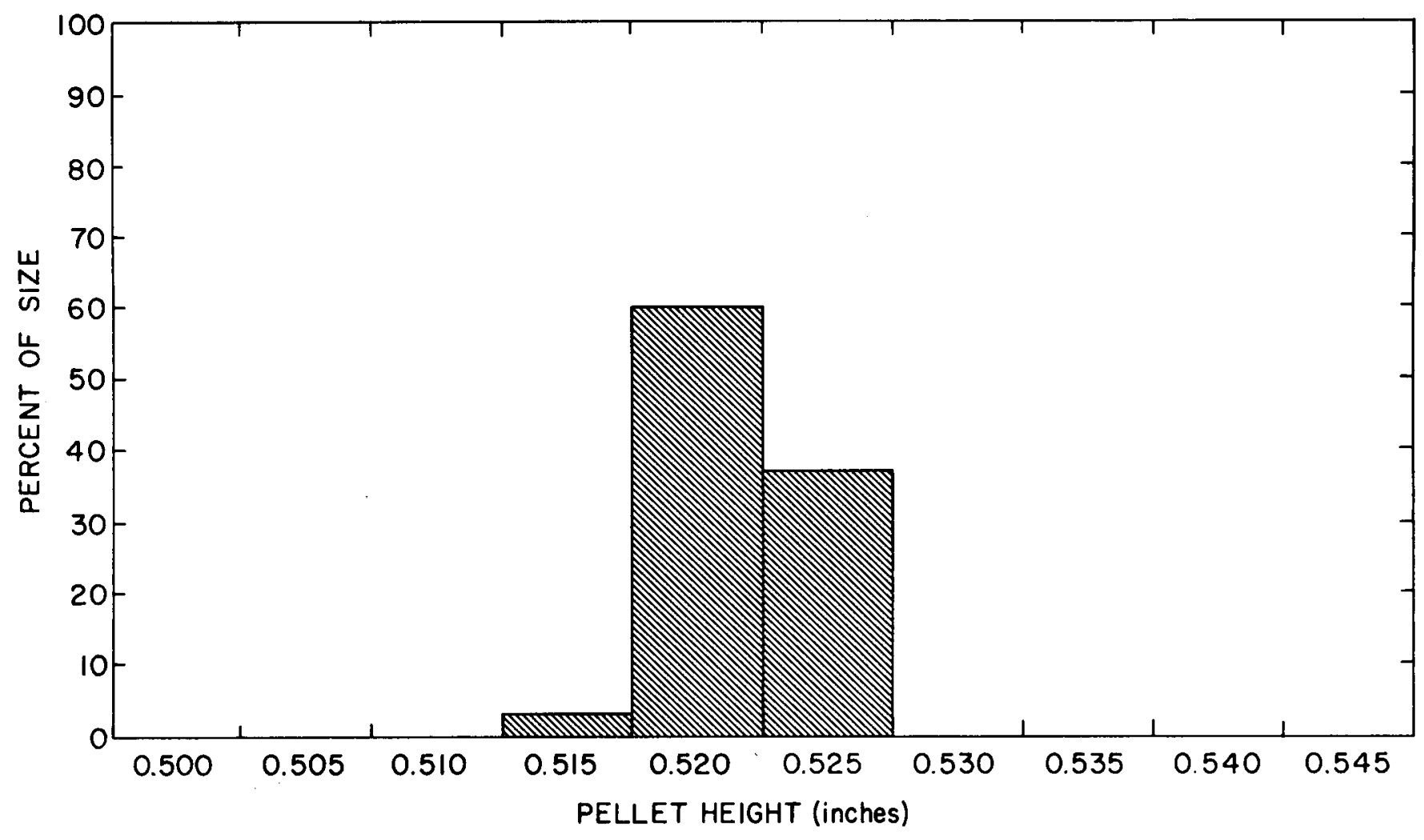


3. N. Fuhrman, L. D. Hower, and R. B. Holden, "Low Temperature Sintering of Uranium Dioxide," J. Am. Ceram. Soc., 46 (1963) 114-121.

4. J. F. Carpenter, C. W. Kuhlman, and R. A. Nelson, "Characterization of Uranium Dioxide Powders Final Report," UNC-1004.

5. R. J. Bard, J. P. Bertino, and D. L. Banker, “Activating Uranium Dioxide," Ind. \& Eng. Chem., 53 (1961) 1003-1006.

6. G. H. Chalder, N. F. H. Bright, D. L. Peterson, and L. C. Watson, "The Fabrication and Properties of Uranium Dioxide Fuel," Proc. 2nd Geneva Conf., Vol. 6 (1958) 590-604.

7. R. Kiessling and U. Runfors, "Sintering of Uranium Dioxide," TID-7546 Book 2 (1958) 402-413.

8. T. Nishijima, T. Kawada, and H. Kitagawa, "An Improved Process for Fabrication $\mathrm{UO}_{2}$ Pellets," J. Nucl. Mat., 16 (1965) 184-189.

9. C. M. Walter, "Review of Status of SelfDiffusion in US, UN, UO ${ }_{2}$, and UC," ANL-7094. (1966). 
RFP-1255

$\bullet$

$\odot$

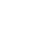

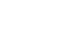

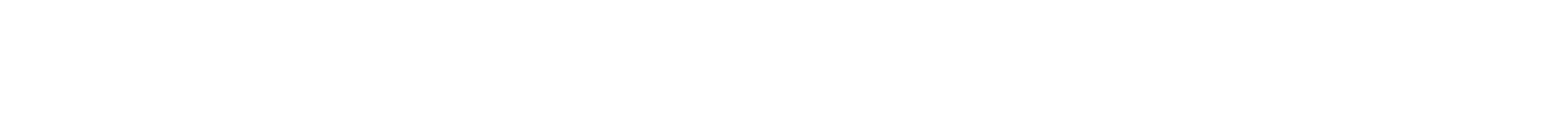

(1)

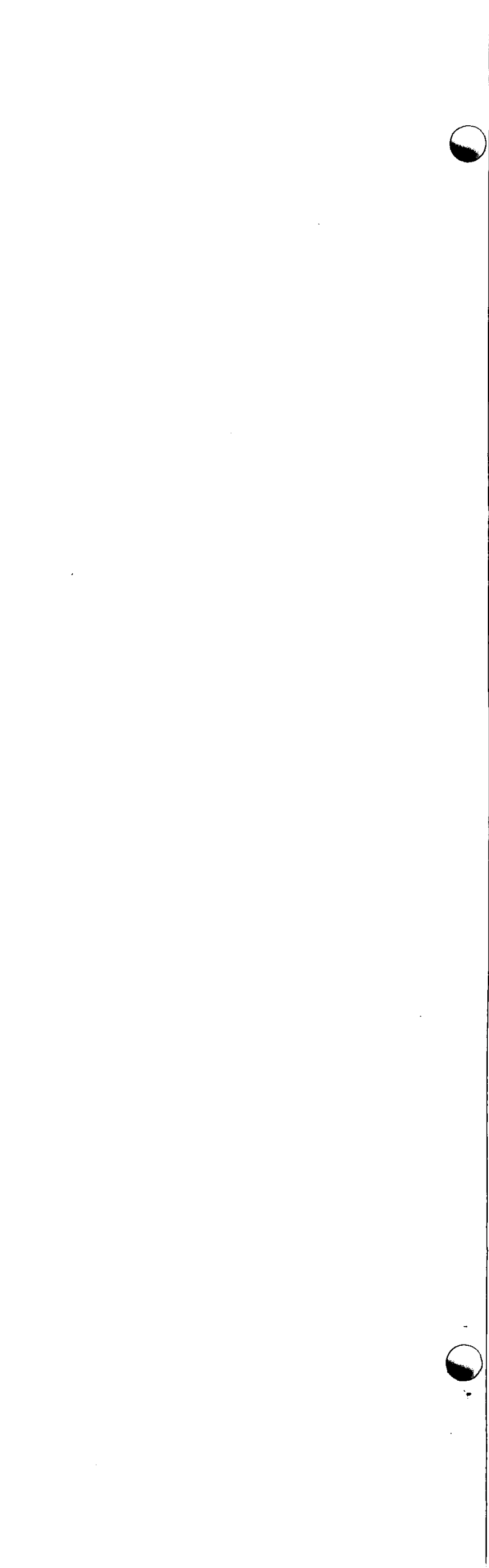




\section{Appendix A: Literature Survey of Fabrication of $\mathrm{UO}_{2}$.}

The accompanying list of references and abstracts are the result of a literature survey on conventional (cold press and sinter) fabrication of $\mathrm{UO}_{2}$. The survey is not complete because of the immense amount of literature in the field, but it is representative.

1

G. H. Chalder, N. F. H. Bright, D. L. Peterson, and L. C. Watson, "The Fabrication and Properties of Uranium Dioxide," Proc. 2nd Geneva Conf., Vol. 6 (1958) 590-604.

Data are presented on the effect of various physical properties of $\mathrm{UO}_{2}$ on its sintering behavior. Various binders and increased residual carbon contents are also evaluated in relation to sintered densities and overall pellet appearance. Sintering aids such as $\mathrm{TiO}_{2}, \mathrm{Nb}_{2} \mathrm{O}_{5}$, and $\mathrm{V}_{2} \mathrm{O}_{5}$ were shown to enhance sintering. Various combinations of hydrogen, nitrogen, argon, and carbon dioxide, (wet \& dry) were also evaluated.

2

Sintered Uranium Dioxide: Sintering Technique and Behavior Under Irradiation - Quarterly Report No.'s 2, 3, 5, 6, and 8, EURAEC-57, 194, 254, $322,478$.

Sintering characteristics of $\mathrm{UO}_{2}$ powders with high surface areas were investigated. Pressing pressure, sintering times and temperatures, and atmospheres were also studied.

3

L. C. Watson, Production of Uranium Dioxide for Ceramic Fuels, TID-7546, Book 2 (1958) 384-401.

Uranium dioxide powder suitable for forming and sintering into high-density ceramic fuel may be prepared by hydrogen reduction of ammonium diuranate. Some of the variables in the preparation of ammonium diuranate and in its subsequent reduction of uranium dioxide have been investigated. The aim was to define the conditions for making a readily sinterable uranium dioxide powder of consistent properties.

Ammonium diuranate was prepared by both batch and continuous precipitation. The effect of varying the precipitation conditions was shown by determining the sintered density of the uranium dioxide pellet prepared from the ammonium diuranate under standard conditions. The effect of varying the reduction conditions was demonstrated.

The results show that the sintering properties of the uranium dioxide are insensitive to reduction conditions but are affected grossly by variations in the ammonium diuranate preparation.

Methods of preparing uranium dioxide that will sinter to a density consistently greater than 10.0 $\mathrm{g} / \mathrm{cm}^{3}$ are given for both batch and continuous precipitation.

Two relatively simple measurements, air permeability and tap density, were made routinely on both ammonium diuranate and uranium dioxide powders. These measurements can be used to segregate powders of poor sintering characteristics but are not useful in predicting minor differences in sinterability.

4

R. W. Thackray and P. Murray, The Sintering of Uranium Dioxide, AERE-M-R-614 (1950).

The results of cold pressing and sintering uranium dioxide, of composition ranging from $\mathrm{UO}_{2.0}$ to $\mathrm{UO}_{2.2}$ in various atmospheres are detailed in this report. It is shown that defect oxide structures sinter more readily than the stoichiometric composition. With Springfields oxide $\left(\mathrm{UO}_{2.13}\right)$ compacts of high bulk density (greater than $9.5 \mathrm{~g} / \mathrm{cm}^{3}$ ) can be obtained by sintering in argon at $1100^{\circ} \mathrm{C}$ to $1500^{\circ} \mathrm{C}$.

The sintering behavior of the uranium oxide phase $\mathrm{UO}_{2.0}$ to $\mathrm{UO}_{2.2}$ (and of other oxides, e.g. $\mathrm{MgO}$ and $\mathrm{Al}_{2} \mathrm{O}_{3}$ ) has been considered thermodynamically. It is found that the application of the absolute reaction rate theory provides a unifying hypothesis for the oxides considered and that the important factor in sintering is the free energy of activation of the process.

From these thermodynamic considerations and the assumption that diffusion plays a major part in sintering, a physical model of the sintering of 
$\mathrm{UO}_{2}$ to $\mathrm{UO}_{2.2}$ is suggested. It is pointed out that theories of sintering based solely on plastic flow/yield point mechanisms cannot explain the sintering of these oxides.

5

J. Glatten, H. R. Hoge and B. E. Schaner, "Fabrication of Dense $\mathrm{UO}_{2}$ Cylindrical Compacts by Cold Pressing and Sintering," WAPD-126 (1955).

Pressing and sintering characteristics of Mallinckrodt hydrogen reduced $\mathrm{UO}_{2}$ powder are presented. Punch and die factors influencing punch and die design are described. Density and shrinkage data for sintered $\mathrm{UO}_{2}$ are given. A graphite resistor sintering furnace is described.

\section{6}

R. Hauser and A. Porneuf, "Frittage Industrial De L'Oxyde D'Uranium En Forir Continu," New Nuclear Materials Including Non-Metallic Fuels, Vol. 1, IAEA (1963) 137-153.

"Industrial Sintering of Uranium Oxide in a Continuous Furnace." Performed under a USAEC-Euratom research contract. CICAF (Compagnie industrielle de combustibles atomiques frittes) was asked by the French Atomic Energy Commission to design and construct a continuous furnace sintering under a reducing atmosphere at high temperature.

The characteristic features of the furnace are; automatic operation, rigorous control of presintering and sintering atmospheres, flexibility of temperature regulation so that the thermal cycle can be adjusted to the product to be sintered, and high output ( 5 tons of uranium oxide per month). It can operate continuously up to $1700^{\circ} \mathrm{C}$, the presintering taking place at a lower temperature $\left(800^{\circ} \mathrm{C}\right)$ in a preliminary furnace which forms an integral part of the whole. The sintering atmosphere is cracked ammonia or pure hydrogen; the presintering atmosphere is a mixture of about $10 \%$ hydrogen and $90 \%$ nitrogen.

The sintered pellets densify to above $97 \%$ of theoretical density, with a total dispersion of less than $1 \%$. Structurally, they are equiaxed grains of about $10 \mu \mathrm{m}$. It was established that the stoichiometric variation of the uranium oxide sintered in a continuous furnace was less than 0.005 .
7

G. Jakobsen, "Some Experiences with Statistical Quality Control in Production Sintering of Uranium Dioxide," New Nuclear Materials Including NonMetallic Fuels, Vol. 1, IAEA (1963) 341-348.

"Some experience with statistical quality control in production sintering of uranium dioxide." The author describes some experiences in the use of statistical quality control in the manufacturing of $\mathrm{UO}_{2}$ for reactor and experimental use. This method has been used for control of the pressing of green pellets and revealed a systematic drift in the process. The sintering furnaces have been shown to give a product with properties varying according to the position of the pellets in the furnace. The drift in the pressing operation and the variation in sintered density according to position can be used to obtain a very uniform product.

8

R. Von Scheibe, "Herstellung von UranoxydSinterkorpern,” Keram. Zeit., 14 (1962) 575-584.

"Preparation of sintered urania bodies." Following a general survey of the properties required of a fissile material, the factors which influence the densification of $\mathrm{UO}_{2}$ in the cold-compaction and sintering processes are discussed. Basic facts about the oxygen compounds of uranium, which are important for the understanding of the sintering process are mentioned. The various ways of preparing $\mathrm{UO}_{2}$ powders as well as additional methods of making dense $\mathrm{UO}_{2}$ bodies are listed.

9

U. Runfors, "Sintrad Urandioxid Som

Reaktorbransle," Sven. Kem. Tidskr., 79 (1967) 206-216.

"Sintered Uranium Dioxide as Reactor Fuel." A review is made of the requirements on sintered $\mathrm{UO}_{2}$ as a reactor fuel in water-cooled reactors. The influence of these demands on the manufacturing steps is discussed. One example is treated in more detail. By variation of one parameter only, the temperature of reduction of $\mathrm{UO}_{3}$ to $\mathrm{UO}_{2}$, the properties of the $\mathrm{UO}_{2}$-powders can be varied within a wide range. These properties, (e.g., the specific surface area) determines the pressability and the sinterability of the powder as well as the properties of the pressed and sintered pellets. In order to achieve the properties desired of $\mathrm{UO}_{2}$ under reactor operation, as well as economic production, both powder 
manufacturing methods and pelletizing parameters have to be carefully chosen.

10

R. Kiessling and U. Runfors, "Sintering of Uranium Dioxide," TID-7546 Book 2 (1958) 402-413

Problems are discussed about the formation of carbides during the sintering operation. It is proposed that these carbides are formed from the carbon containing residues remaining after the binder burnout. Another source is from graphite furnaçe tubes used in sintering. Elimination of the carbides is important in producing high quality carbide-free pellets.

11

E. A. Evans, "Fabrication and Enclosure of Uranium Dioxide," TID-7546, Book 2 (1958) 414-431.

Uranium dioxide compacts of high density can be economically produced by conventional ceramic processes such as cold pressing, isostatic pressing, hot pressing, extrusion, and slip casting.

Greatly reduced costs and improved quality have been made possible by new powder treatments and fabrication techniques. Typical of the recent developments are (1) powder activation by reduction in a fluidized bed, (2) combined powder compaction and cladding by swaging (without subsequént sintering), and (3) finishing of sintered ware by belt centerless grinding.

To overcome the disadvantage of poor neutron economy, $\mathrm{UO}_{2}$ fuel assemblies require not only high-density oxide but also an efficient arrangement of the fuel. It is now economically feasible to fabricate $\mathrm{UO}_{2}$ cores for relatively simple fuel assemblies which will meet this requirement.

Problems of providing safe, durable, and economical enclosures for $\mathrm{UO}_{2}$ fuel cores are rapidly being solved. Techniques have been developed for forming and assembling tubing, end fittings, and supporting members from alloys of zirconium, iron, and aluminum. Less conventional techniques, such as vacuum casting of zirconium alloys and highfrequency welding, are being studied. Standardization of fabricating processes and fuel-element designs is an extremely desirable objective which will be partially realized as the operating behavior of $\mathrm{UO}_{2}$ fuel elements becomes better understood.
12

S. Fareeduddin, et. al., "Fabrication of Uranium Oxide Fuel Elements at Trombay," Proc. 3rd Geneva Conf., Vol. 11 (1964) 345-351.

In connection with lattice parameter experiments in the zero-energy reactor and keeping in view the future requirements, production and fabrication of uranium oxide fuel bodies have been investigated on a semi-industrial scale. Active uranium oxide powder that sinters consistently to $94 \%$ theoretical density, and above, has been produced with the use of aqueous ammonia within a fairly wide range of production conditions, i.e., precipitation, calcination and reduction. Although some of the variables affect powder properties to some extent, they are not found to influence markedly the final, sintered-density perhaps because of the introduction of further operations. comparatively, the powders pertaining to runs 56 and 58 were found to be superior, and from them 2 tons of sintered pellets were made with a density exceeding $94 \%$ theoretical which were assembled in 19 rod cluster elements for SERLINA.

13 C. J. Baroch, "Design and Fabrication of Fuel Rods Containing Low Temperature Sintered Pellets," GEAP-4257 (1963).

The $\mathrm{UO}_{2}$ pellets, were prepared in the following manner:

1. $\mathrm{UO}_{2}$ powder was activated by a thermal process involving oxidation, pyrohydrolysis, and subsequent reduction with hydrogen.

2. The activated powder was roasted in air to introduce an excess of oxygen.

3. The oxidized powder was mixed with a binder, sized, and then pressed into pellets using a pressure of $20 \mathrm{tsi}$.

4. The green pellets were sintered in nitrogen for one hour at $1150^{\circ} \mathrm{C}$ and then in hydrogen for $2-1 / 2$ hours.

The sintered pellets met dimensional specifications and, therefore, grinding was not necessary. The pellets were then inserted into stainless steel tubes which were sealed by welding in end plugs. 
14

D. S. Jovanovie, E. M. Kostic, I. G. Momcilovic, V. J. Petrovic, and M. M. Ristic, "Ceramic Fuel Obtained from Metallic Grade $\mathrm{UO}_{2}$ Powder,' Proc. 3rd Geneva Conf., Vol 11 (1964) 341-343.

The objective of this report is to contribute to the study of the possibility of using the metallic grade uranium dioxide powder with special reference to:

1. The study of the effect of furnace atmosphere on the sintering of metallic grade $\mathrm{UO}_{2}$ powders, and

2. The determination of possible characterizations of $\mathrm{UO}_{2}$ powders by sedimentation analysis and by the technique earlier described regardless of orthokinetic flocculation.

The results prove that the metallic grade $\mathrm{UO}_{2}$ powder can be used for the production of high density ceramic fuels.

15

R. Delmas and J. Holder, "Etude De La Preparation Du Bioxyde D'Uranium Frittable Pour La Fabrication of Combustible D'EL4," New Nuclear Materials Including Non-Metallic Fuels, Vol 1, IAEA (1963) 95-108.

"Study of the Preparation of. Sinterable Uranium Dioxide for the Fabrication of Fuel for the EL4.", The authors briefly recall the research which led them to plan the unit, described elsewhere, for preparation by reduction of the 20 tons of enriched uranium required for the initial loading of the EL4 reactor.

The qualities of the uranium dioxide obtained are shown to depend not only on the conditions of reduction, but also on those of precipitation and calcination of the intermediate products between the nitrate and the higher oxide.

Particular attention is paid to carrying out reduction under exactly defined conditions. This is possible thanks to the use of a revolving-tube, continuous-operation apparatus.

Owing to the regular contact between the solid and the reducing gas, which permits excellent heat exchange, the uranium dioxide prepared by this method is very homogeneous and well suited to sintering.
The apparatus as designed and constructed can produce $10 \mathrm{~kg}$ of uranium dioxide per hour.

Hundreds of kilograms of dioxide have been prepared and sintered on an industrial scale. This operation is described in the paper submitted by the Compagnie industrielle des combustibles atomiques frittes.

The average density of the sintered pellets is 10.5. Density is never less than 10.4, and for certain dioxides may reach 10.8 . This reducing technique can also be used for the preparation of 16 dioxides to be shaped by cold extrusion.

G. W. Cunningham, "United States Experience in Powder Metallurgy for Nuclear Applications," Powd. Met., 10 (1967) 78-93.

The types of problems encountered in the use of powder components for nuclear reactor cores are discussed. Examples are given of processes and experience related to the application of standard powder techniques to nuclear materials, use of novel methods for the production of nuclear materials, adaptation of commercial powder products for 17 in-reactor use, and development of unique materials.

A. J. Caputo and J. E. Perry, "Production, Precision Forming, and Sintering of Ceramin-Grade $\mathrm{UO}_{2}$," Y-1301 (1961).

An essentially continuous process was developed to produce a high-quality, sinterable $\mathrm{UO}_{2}$ powder. Aqueous solutions of uranyl fluoride and/or uranyl nitrate were chosen as the uranium feed material because of their widespread availability and to demonstrate the flexibility of the process. The uranium solutions were contacted with ammonium hydroxide to precipitate an ammonium diuranate (ADU) slurry. After filtering, reslurrying, and drying, the $\mathrm{ADU}$ was converted to $\mathrm{U}_{3} \mathrm{O}_{8}$ in a rotating kiln at a temperature of $450^{\circ}-500^{\circ} \mathrm{C}$ using a steamnitrogen-air atmosphere. A rotating kiln was also used to reduce the $\mathrm{U}_{3} \mathrm{O}_{8}$ to $\mathrm{UO}_{2}$ at $570^{\circ}-650^{\circ} \mathrm{C}$ using a hydrogen-nitrogen-steam atmosphere. The resulting pyrophoric powder was stabilized by a controlled oxidation to allow safe handling in air while maintaining a surface area of $5-8 \mathrm{~m}^{2} / \mathrm{g}$.

The powder was prepressed at $15,000 \mathrm{lb} / \mathrm{in}^{2}$, reground, and formed at relatively low pressures $\left(6,000-9000 \mathrm{lb} /\right.$ in. $\left.^{2}\right)$ in a double-acting automatic press without the use of binders or lubricants mixed with the powder. The compacts were sintered in an atmosphere of purified hydrogen at temperatures of about $1750^{\circ} \mathrm{C}$ and had a high density $(94 \%$ of 
theoretical) with clean, chip-free surfaces. Even though there was a $25 \%$ dimensional shrinkage on sintering, the consistency of the powder made it possible to maintain a diameter tolerance of \pm 0.001 to \pm 0.003 inch depending upon size. Compacts thus formed ranged in size from: (1) discs formed with a 4-inch o.d. which sintered to a 3-inch o.d. (2) bushing-type cylinders (referred to as pellets) formed with a 0.94 inch o.d. and 0.44 inch i.d. which sintered to 0.70 inch o.d. and 0.32 inch i.d., and (3) solid cylinders formed with a 0.56 inch o.d. which sintered to a 0.42 inch o.d. The lengths of the sintered compacts were varied up to one inch while maintaining a tolerance of \pm 0.005 .

The pilot plant program, described in this report, shows the feasibility of simplified methods of production of good quality $\mathrm{UO}_{2}$ powder and shapes. The reported results are based on operations closely approximating production conditions. It was demonstrated that this process is capable of producing a consistent quality product with significant cost savings over other processes now in use.

\section{8}

P. E. Trent, "Preparation of Ceramic Uranium Dioxide Compacts," Y-DA-1733, (1957)

Experience in pressing, sintering, and fabricating uranium dioxide pellets to meet the requirements for high density and close dimensional tolerances. has been well advanced at the Oak Ridge Y-12 Plant.

The original work on uranium dioxide powders and the pellets that were fabricated from these powders was performed for the Oak Ridge National Laboratory's Gas-Cooled Reactor. Since the development of a suitable procedure for producing both powder and compacts, both have been requested by others, primarily for experimentation and evaluation.

Normally the requestor wants compacts of high density and with close dimensional tolerances and clean, chip-free edges and surfaces. However, one request presented an additional requirement. Not only were the pellets to meet the requirements for close dimensional tolerances, but the densities of the compacts were to range from 8.2 to $10.4 \mathrm{~g} / \mathrm{cm}^{3}$ in $0.2 \mathrm{~g} / \mathrm{cm}^{3}$ increments and with no deviation greater than $\pm 0.01 \mathrm{~g} / \mathrm{cm}^{3}$ within an increment. Six pellets were needed in each of the twelve density categories. This request was met and through the experience that was gained it is now possible to produce satisfactory pellets with densities as low as $8.0 \mathrm{~g} / \mathrm{cm}^{3}$.

19

R. P. Levey, Jr., "The Cold Pressing of Sinterable $\mathrm{UO}_{2}$, " Y-1340 (1960).

The pressing of sinterable $\mathrm{UO}_{2}$ powders into cylindrical shapes over a range of length-to-diameter ratios and pressures has been studied. The magnitude of the die wall powder friction was evaluated both by direct measurement and by the actual density reduction in pellets under various pressing conditions. At a forming pressure of $8238 \mathrm{psi}$, a variation in L/D of from 0.1 to 2.0 accounts for an over-all density change $>20 \%$. Several density pressure correlations, either purely empirical or based upon a simple model, are suggested and the limitations of each are discussed. The compressibility of $\mathrm{UO}_{2}$ is compared with that of several other sinterable materials. $\mathrm{UO}_{2}$ appears to be less compressible than all other materials tested-safe for tungsten powder. The tensile strength of green $\mathrm{UO}_{2}$ compacts was measured, and a minimum strength of $30 \mathrm{psi}$ is suggested for acceptable handling characteristics. The effect of prepressing powder on the pressure-density relationship is evaluated and shown to increase density and reduce friction. The evaluation of a new die design for use with sinterable $\mathrm{UO}_{2}$ is described. While the pressure ceiling at $L / D=1$ is $-10,000$ psi with conventional dies, the new design permits pressing up to 100,000 psi under the same conditions.

20

C. Placek and E. D. North, "Uranium Dioxide Nuclear Fuel," Ind. \& Eng. Chem., 52 (1960) 458-464.

21

G. D. Collins, "Fabrication Cost Estimate for $\mathrm{UO}_{2}$ and Mixed $\mathrm{PuO}_{2}-\mathrm{UO}_{2}$ Fuel," GEAP-3824 (1962).

22

J. F. Carpenter, C. W. Kuhlman, and R. A. Nelson, "Characterization of Uranium Dioxide Powders Final Report," UNC-1004.

The extensive use of ceramically active $\mathrm{UO}_{2}$ for the production of power reactor fuel elements has intensified the need for a simple test to define the ceramic activity of $\mathrm{UO}_{2}$ powders. To survey the applicability of a wide variety of tests on a broad spectrum of $\mathrm{UO}_{2}$ powders. The tests considered (detailed descriptions are given in Appendix B) included among others. 
1. Bulk density

2. Tap density

3. Surface area

4. Fisher sub-sieve size

5. Oxygen to uranium ratio

6. Oxidation temperature

7. Particle size determination of the raw oxide

8. Particle size determination on the pressed and repulped $\mathrm{UO}_{2}$ (free-flowing powder obtained by breaking up pressed green pellets - see Appendix E)

Most of the tests considered showed a general correlation with sinterability, but were relatively inconsistent. Apparently one of the difficulties in the majority of the tests considered was the failure to predict the effect of pressing-an operation largely independent of the particle size of the raw oxide-on the particle size or surface area of powder just prior to sintering. Even with adjustment for this operation, the B.E.T. surface area was not a satisfactory measure of the final fired density which might be achieved. The B.E.T. results, however, did correlate well with the percent shrinkage experienced early in the sintering operation.

The results of particle size determination by sedimentation analysis on pressed and repulped oxides were easily the most consistent in predicting the final sintered density, though even this test was far from infallible. The use of this test to minimize the testing burden for oxide producers and consumers deserves consideration.

23

Characterization of Uranium Dioxide, TID-7637, Meeting on Characterization of Uranium Dioxide held at Oak Ridge National Laboratory, Oak Ridge, Tennessee, December 12-13, 1961.

24

D. R. Stenquist, B. Mastel, and R. J. Anicetti, "Note on Correlation of Surface Characteristics of Uranium Dioxide Powders with the ir Sintering Behavior," J. Am. Ceram. Soc. 41 (1958) 273-274.

25

V. K. Moorthy, A. K. Kulkarni and S. V. K. Rao, "Relation Between Origin, Powder Characteristics and Sintering Treatment on the Densification and Microstructure of Compacts of Urania and Thoria," Proc. 3rd Geneva Conf., Vol 11 (1964) 386-392.
26

Y. Carteret, M. Portnoff, J. Elston, and R. Caillat, “'Influence D L' Atmosphere Sur La Reactivite Des Pondres D'Oxyde D'Uranium,"'Reactivity of Solids, American Elsevier Publishing Company, Inc., (1961) 540-548.

The reactivity of powders of uranium dioxide has been measured by the study of the change of their specific surface with temperature either in vacuo or under a hydrogen or argon atmosphere. The influence of the non-stoichiometry has also been examined.

The experimental results can be summarized as follows:

1. In hydrogen the decrease of the specific surface of the $\mathrm{UO}_{2}$ powder starts at $900^{\circ} \mathrm{C}$ and then progresses very slowly.

2. In argon or in vacuo, the specific surface of a stoichiometric uranium dioxide diminishes rapidly between $700^{\circ}$ and $800^{\circ} \mathrm{C}$, and the more rapidly as the initial surface is larger.

3. Finally, the specific surface starts diminishing at $500^{\circ}$ if traces of oxygen are introduced before the experiment in vacuo.

In conclusion: at a given temperature, the reactivity of an uranium dioxide powder is related to its surface. It is higher under vacuum or in argon than in hydrogen. It is higher for the nonstoichiometric uranium dioxide powder than for the stoichiometric one. These results can be explained by the adsorption of hydrogen on the uranium dioxide surface. The desorption is only progressive in an atmosphere of hydrogen but complete at $700^{\circ}$ in vacuo. It may be that both the hydrogen desorption and the oxygen adsorption cause the formation of structural defects which help the diminution of the surface of the uranium dioxide.

The technological results concerning the sintering of the uranium dioxide are in good agreement with the conclusions concerning the powders.

\section{7}

M. J. Bannister, “The Storage Behavior of Uranium Dioxide Powders - Review Article," J. Nucl Mat., 26 (1968) 174-184. 
The storage behavior of uranium dioxide powder is reviewed. Topics covered include the amount of oxygen taken up under storage conditions, the effects of extra oxygen on the fabrication and irradiation behavior of uranium dioxide, the basic oxidation processes, the pyrophoric reaction of uranium dioxide powders in air, and the protection of uranium dioxide against oxidation. The pyrophoric process in air at room temperature is shown to be the result of rapid chemisorption of oxygen, and a the ory explaining this effect is developed. The individual rate equations for the basic oxidation processes operative at room temperature are combined to give a law for the overall oxidation behavior at room temperature, and comparisons are made with data in the literature.

28

R. J. Bard, J. P. Bertino, and D. L. Banker, "Activating Uranium Dioxide," Ind. \& Eng. Chem., 53 (1961) 1003-1006.

29

E. Paricio, J. A. Alonso, and J. D. Pedregal, "Influencia De La Historia Previa De La Materia Prima Sobre La Sinterizacion $\mathrm{Del} \mathrm{UO}_{2}$," New Nuclear Materials Including Non-Metallic Fuels, Vol 1, IAEA (1963) 191-203.

"Influence of the previous history of the raw material on sintering of $\mathrm{UO}_{2}$." An account is given of the experimental principles underlying the pro- duction process of a $\mathrm{UO}_{2}$ pellet plant. In this process, advance determination of the.particle-size distribution characteristics of the raw material is secured not by means of controlled precipitation but by the crushing and grading of powders. The uranium oxides tested in this work are conventional materials, representing types of fabrication which differ by origin and method used. A study of the pellets obtained shows the potentialities and limitations of each type of oxide in the process adopted. A description is given of the characteristics of the powders as regards specific area, particle-size distribution, differential and thermogravimetric thermal analyses, and stoichiometry, and of the density, contraction, structure and stoichiometry of the pellets.

30

M. M. Ristic, S. Radic, and B. Zivanovic,

"Characteristic Parameters of Sintering as Measures of the Effect of Compacting Pressure on the Sintering of Uranium Dioxide," Boris Kidric Inst., 14 (1963) 197-205.
An investigation has been made of the effect of compacting pressure on the sintering of uranium dioxide as measured by changes in the characteristic magnitudes of sintering. The obtaining of high densities was not the subject of these investigations.

It has been shown that the density of a uranium dioxide compact changes with compacting pressure according to Rutkowski's equation. An analysis of the change of Lenel's densification parameter as a function of compacting pressure gave a good measure of the effect of compacting pressure on the sintering of uranium dioxide. From data for this characteristic quantity of sintering and Jander's equation, the effect of compacting pressure on the sintering rate has been shown.

In addition, it has been shown how the pore shrinkage parameter changes with compacting pressure.

31

D. R. Stenquist and R. J. Ancetti, "Fabrication Behavior of Some Uranium Dioxide Powders," HW-52748, (1957).

\section{2}

E. H. P. Cordfunke and A. A. Van Der Gressen, "Particle Properties and Sintering Behavior of Uranium Dioxide," J. Nucl. Mat., 24 (1967)

141-149.

The sintering behavior of $\mathrm{UO}_{2}$ has been studied as a function of its preparation conditions, using oxide powders of widely differing morphology. The variables studied are mainly particle size and shape, the calcination temperature and the sinter atmosphere. Their influence on compacting density and sinter density is shown and discussed.

33

U. Runfors, N. Schonberg and R. Kiessling, "The Sintering of Uranium Dioxide," Proc. 2nd Geneva Conf., Vol. 6 (1958) 605-611.

Various processing parameters such as powder processing, compaction, sintering time and temperature, and atmosphere were studied.

34

A. J. Carrea, "Sinterizacion de Dioido De Uranio de Produccion Nacional," Comision Nacional De Energia Atomica, Buenos Aires, Argentina (1963). 
Two procedures are given for fabrication of uranium dioxide pellets. The first consists of sintering at $1200^{\circ}-1400^{\circ} \mathrm{C}$ in argon followed by hydrogen reduction at $1200^{\circ} \mathrm{C}$. The second procedure consists of sintering in an argon plus $3 \%$ hydrogen atmosphere at temperatures between $1200^{\circ}-1400^{\circ} \mathrm{C}$; theoretical densities between 95 and $97.5 \%$ are reported.

\section{5}

A Bel and Y Carteret, "Contribution to the Study of Sintering of Uranium Dioxide," Proc. 2nd Geneva Conf., Vol. 6 (1958) 612-619.

The following phenomena are discussed: (1) the effect of $\mathrm{O} / \mathrm{M},(2)$ the effect of particle size on sinterability, and (3) the activation of powders by increasing the surface area.

36

I. Amato, R. L. Colombo, and A. P. Balzari, "Grain Growth in Pure and Titania-Doped Uranium Dioxide," J. Nucl Mat., 18 (1966) 252-260.

Current literature data of grain growth of uranium dioxide sintered in reducing or neutral atmospheres, and in slightly oxidizing atmospheres, are critically reviewed. It appears that the growth rate is higher in the latter case and that consequently the activation energy calculated by fitting the data to a rate equation is lower.

Grain growth is followed in pure and titania-doped uranium dioxide bodies held for different times at temperatures from $1450^{\circ}$ to $1630^{\circ} \mathrm{C}$ in a hydrogen atmosphere. It is found that the growth rate is higher in the specimens of the latter type, which would be consistent with the idea that titania promotes off-stoichiometry in uranium dioxide; however, the activation energy derived appears to be higher.

The scant reliability of calculations of this kind is discussed and assessed.

37

I. Amato, R. L. Colombo, and A. M. Protti, "Influence of Stoichiometry on the Rate of Grain Growth of $\mathrm{UO}_{2}$, , J. Am. Ceram. Soc., 46 (1963) 407.

38

I. Amato and R. L. Colombo, "The Influence of Organic Additions on the Solarization and Grain Growth of Sintered $\mathrm{UO}_{2}$, 'J. Nucl. Mat., 11 (1964) 348-351.
G. M. Yunus, "Etude De La Croissance Des Grains Dans $\mathrm{L}^{\prime} \mathrm{UO}_{2}$ Fritte Traite A Haute Temperature," New Nuclear Materials lncluding Non-Metallic Fuels, Vol 1, IAEA (1963) 283-306.

"Study of Grain Growth in Sintered $\mathrm{UO}_{2}$ Treated at High Temperature." A number of tests have been carried out in an apparatus in which a cylindrical stack of sintered $\mathrm{UO}_{2}$ pellets can be axially heated by means of a W-wire.

In experiments under controlled temperature conditions, it was shown, in particular, that the transformation of equiaxed grains into basaltic grains begins at $1700^{\circ} \mathrm{C}$.

40

J. R. Mac Ewan, "Grain Growth in Sintered Uranium Dioxide: I Equiaxed Grain Growth; II Columnar Grain Growth," J. Am. Ceram. Soc. 45 (1962) 37-45.

Grain growth was investigated in a $\mathrm{UO}_{2}$ sinter of $94 \%$ theoretical density over the temperature range $1555^{\circ}$ to $2440^{\circ} \mathrm{C}$. The results were in close, but not exact, agreement with a theoretical expression describing grain growth with a polycrystalline matrix. For the material studied the mean grain diameter, D $(\mu \mathrm{m})$ after annealing for $t$ hours at a temperature $\mathrm{T}\left({ }^{\circ} \mathrm{K}\right)$ was given by the equation

$$
D^{2}-D_{o}^{2}=k_{o} t^{0.8} \exp (-87,000 / R T)
$$

where $\mathrm{D}_{\mathrm{o}}$ and $\mathrm{k}_{\mathrm{o}}$ are, respectively, the initial grain size and a proportionality constant. Uranium metal was found in all specimens annealed above $2000^{\circ} \mathrm{C}$. This was taken as evidence that the $\mathrm{UO}_{2}$ lattice can be oxygen-deficient at high temperatures.

41

J. R. Mac Ewan and J. Hayashi, "Grain Growth in $\mathrm{UO}_{2}$ III. Some Factors Influencing Equiaxed Grain Growth," Proc. Brit. Ceram. Soc, 7 (1967) 245-272.

Under is othermal conditions, equiaxed grain growth proceeds in the classical manner as a function of time and temperature.

The effect of five other potential variables has been examined. Increasing the $\mathrm{O} / \mathrm{U}$ ratio from 2.00 to 2.23 , while still retaining the fluorite structure, enhanced the rate of growth by up to four orders of magnitude. The activation energy was determined 
at $\mathrm{UO}_{2,02}$ and was $60 \%$ of the value for $\mathrm{UO}_{2,00}$. The application of a uniform stress, sufficient to cause plastic flow, did not affect growth, but a nonuniform stress caused exaggerated growth in the region of highest stress. Addition of a solute impurity, 0.77 mole $\% \mathrm{CaO}$, decreased the rate of growth below $2400^{\circ} \mathrm{C}$ and increased the activation energy by $25 \%$. Irradiation exposure in a nuclear react or was found to severely inhibit growth. The application of the Zener relationship to a particular sinter, where the change in pore-size distribution was followed during grain growth, indicated that porosity elimination was not rate-controlling.

M. F. Lyons, D. H. Coplin, and B. Weidenbaum, "Analysis of $\mathrm{UO}_{2}$ Grain Growth Data from Out of Pile Experiments," GEAP-4411 (1963).

Data on equiaxed $\mathrm{UO}_{2}$ grain growth from "out-ofpile" experiments have been gathered from all known sources and analyzed to determine the relationship between the grain size developed and annealing temperature and between grain size and the time at temperature. On the basis of the analysis, an equation relating grain size to time and temperature has been selected that appears to best describe the data considered as a whole. The coefficients in this grain growth equation have been evaluated to indicate the variance between . different investigations and/or different $\mathrm{UO}_{2}$ sinters.

The general applicability and limitations of "out-ofpile" grain growth data for the determination of temperatures in the microstructures of irradiated $\mathrm{UO}_{2}$ are discussed. Specific recommendations are made for the conditions under which grain size can be reliably used as a temperature indicator.

The objective in undertaking this analysis on $\mathrm{UO}_{2}$ grain growth was to obtain a working relationship between $\mathrm{UO}_{2}$ grain size and annealing time and/or temperature, and also a measure of the potential variation in the relationship. The intended use of the results was the determination of temperatures based on the grain sizes observed in the postirradiation metallographic examination of the AECEuratom High Performance $\mathrm{UO}_{2}$ Program fuel capsules. The results are being reported in the belief that they will be of use in the analysis of other fuel experiments.
43

I. Amato, R. L. Colombo, and A. M. Protti, "On a Case of Solarization During Steam Sintering of $\mathrm{UO}_{2}$ Pellets," J. Nucl. Mat. 8 (1963) 271-272.

44

I. Amato and R. L. Colombo, "Grain Boundary Precipitates in Over-Sintered $\mathrm{UO}_{2}$," J. Nucl. Mat. 10 (1963) 261-262.

45

I. Amato, R. L. Colombo, and A. M. Protti, "Pore Growth During Solarization of Sintered $\mathrm{UO}_{2}$," J. Nucl. Mat., 13 (1964) 265-267.

46

I. Amato and R. L. Colombo, "A Note on the Influence of Local Variations in $\mathrm{O} / \mathrm{U}$ Ratio During $\mathrm{UO}_{2}$ Pellet Sintering," Energ. Nucl. 11 (1964) 217.

47

N. A. L. Mansour, A. M. Gadallal and J. White, "Causes of Residual Porosity in Sintered Uranium Dioxide," Powd. Met., 12 (1963) 108-121.

The densification characteristics of a sample of uranium dioxide approximating in composition to $\mathrm{UO}_{2.1}$ have been investigated as a function of compacting pressure, firing temperature and time, and sintering atmosphere. Fired densities achieved were found to be markedly dependent on the initial as-pressed density, and microscopic examination of pellets after different firing treatments showed that this behavior was associated with internal shrinkage, leading to fissuring in pellets of low initial density. This imposed a limit on both densification and grain growth. Pellets have aspressed densities of $50 \%$ of theoretical, which was sufficient to eliminate fissuring, sintered to densities of $0.98 \%$ of theoretical in $2 \mathrm{hr}$ at $1400^{\circ} \mathrm{C}$ in nitrogen and argon and then expanded. Subsequently shrinkage was resumed and was still continuing after $32 \mathrm{hr}$ sintering. A study of the pore-size distribution after various sintering times suggests that the expansion may be associated with diffusion of gas from small to large pores. Grain growth was found to obey a relation of the form $D^{3}-D_{0}{ }^{3}=K\left(t-t_{0}\right)$, $D$ and $D_{0}$ being the average grain diameters at times $t$ and $t_{0}$.

48

A. H. Webster and N. F. H. Bright, "The Effect of Furnace Atmosphere on the Sintering Behavior of Uranium Dioxide," NP-6667 (1958). 
The properties of compressed uranium dioxide shapes have been examined after sintering in atmospheres of hydrogen, nitrogen + hydrogen, argon, wet argon, argon + oxygen, nitrogen, wet nitrogen, nitrogen + oxygen, and steam over the temperature range $1200^{\circ}$ to $1500^{\circ} \mathrm{C}$. Attention has been given particularly to the control of the non-stoichiometric oxygen in the oxide before, during, and at the completion of the sintering. It has been shown that the presence of non-stoichiometric oxygen up to a certain limit is desirable in the oxide to be sintered, and that it is also desirable that this non-stoichiometric oxygen should remain in the oxide while the sintering is taking place if it is desired to achieve good sintering at relatively low temperatures. However, the excess of oxygen should be removed to yield an essentially stoichiometric oxide on cooling in order that the product may have satisfactory characteristics when used as a fuel element. The atmospheres listed above have been examined with a view to achieving control of the non-stoichiometric oxygen at the various stages, and a recommended procedure to achieve the desired result has been outlined. Use has been made of the published thermodynamic data for the uranium dioxide/oxygen system in interpreting the results and in forecasting suitable sintering conditions.

49

J. Williams, E. Barnes, R. Scott and A. Hall, "Sintering of Uranium Oxides of Composition $\mathrm{UO}_{2}$ to $\mathrm{U}_{3} \mathrm{O}_{8}$ in Various Atmospheres," J. Nucl. Mat., 1 (1959) 28-38.

The behavior of uranium oxides of compositions in the range $\mathrm{UO}_{2}$ to $\mathrm{U}_{3} \mathrm{O}_{8}$ on sintering in atmospheres of argon, nitrogen, carbon dioxide, vacuum and hydrogen at various temperatures is described. Increase in surface area and departure from stoichiometric composition improve sintering performance. The beneficial effect of the additional oxygen is believed to be due chiefly to the increased high-temperature plasticity of the non-stoichiometric oxide. Additional effects may arise from the increase in surface area accompanying the phase change in oxides of oxygen/uranium ratio above $\approx 2.06$, from the increased volatility of the non-stoichiometric oxide, and removal of adsorbed or absorbed hydrogen by the oxygen in excess of stoichiometry. The practical implications of the experimental results are discussed.
50

A. Bel, R. Delmas, and B. Francois, "Frittage De L'Oxyde D'Uranium Dans L'Hydrogene A $1350^{\circ} \mathrm{C}, "$ J. Nucl. Mat. 3 (1959) 259-270.

Sintering in argon, of oxides of large specific surface area, produces a more coarse-grained product $(5-10 \mu)$ than does hydrogen sintering; the density is the same in each case. Departure from stoichiometric composition of the powders does not appear to influence the density of the sintered compact.

The sintering, in hydrogen, of various oxides of specific surface area, obtained from ammonium uranate and uranium peroxide, was studied in a systematic way. With a given specific surface area, the final density varied as a function of the sintering temperature, with a maximum density for a particular temperature. This temperature is lowest when the specific surface area of the powder is the greatest.

A process is described for the preparation of uranium oxide powder from ammonium uranate and its sintering in hydrogen at $1350^{\circ} \mathrm{C}$; in this way a fine-grained product of density 10.6 can be obtained.

51

J. Williams, "The Sintering of Uranium Dioxides" (Discussion of previous paper), J. Nucl. Mat., 2 (1960) 92-93.

It was proposed that conclusions by the French were incorrect on (1) the effect of stoichiometry on sintering rates, (2) the effect of water vapor on final sintered densities, and (3) oversintering.

52

A. Bel, R. Delmas, and B. Francois, "Le Frittage Des Oxydes D'Uranium," J. Nuc. Mat., 2 (1960) 192-193.

53

A. J. Carrea, "Sintering of Uranium Dioxide in an Atmosphere of Controlled Hydrogen Content," J. Nucl. Mat., 8 (1963) 275-277.

54

W. E. Baily, J. C. Danko, H. M. Ferrari, and

R. Colombo, "Steam Sintering of Uranium Dioxide," Ceram. Bull., 41 (1962) 768-772. 
Effects of a steam atmosphere on the sintering of uranium dioxide were investigated. Experiments were performed on two different powders at several temperatures and for varying periods of time.

Dilatometric studies were conducted on the pellets during the sintering cycle. Steam sintering of $\mathrm{UO}_{2}$ was found to be more effective than hydrogen sintering. Appreciable sintering occurred at temperatures as low as $750^{\circ} \mathrm{C}$. The heating and cooling atmospheres were found to have negligible effects on the sintered characteristics of the specimens.

55

"Steam Sintering of Uranium Dioxide," EURAEC 321 (1962).

Steam sintering experiments are over. Of the three $\mathrm{UO}_{2}$ powders examined, CEA was found to be the most easily sinterable, closely followed by MCW. The CNEN powder did not attain high fired density and showed a definite tendency to solarize. A similar trend exists also for hydrogen sintering, but differences are much less important.

Evolution of grain growth and the variation of pore number during densification was followed through micrographic analysis; evidence of discontinuous grain growth at relatively low temperatures was found only for CNEN powder.

The energy of activation for steam sintering was measured for the three powders. Results were found to depend on the powder, but still were in the range of the values to be found in the literature, except that for comparatively low densities the energy is much larger.

It has been proved that the density of the inner part of a sintered pellet is lower than that of the outer part for hydrogen sintering, but not for steam sintering.

Sintering of $\mathrm{UO}_{2} / \mathrm{U}_{3} \mathrm{O}_{8}$ mixtures in inert gas was found to closely resemble steam sintering, except that in order to achieve high densities it was necessary to reduce to a minimum the amount of binder added to the powder.

Considerable $\mathrm{x}$-ray work was done to check what happens to $\mathrm{UO}_{2} / \mathrm{U}_{3} \mathrm{O}_{8}$ mixtures prior to sintering, but the evidence gained up to now is not yet conclusive.
56

C. A. Arenberg and P. Jahn, "Steam Sintering of Uranium Dioxide," J. Am. Ceram. Soc., 41 (1958) 179-183.

The following variables were considered in an investigation of the sintering of uranium dioxide: (1) sintering aids, i.e., small additions of substances that might aid the densification process, (2) soaking temperature, (3) soaking time,

(4) furnace atmosphere, and (5) particle size of the uranium dioxide. The incipient sintering temperature, the effect of binders, and the effect of fabricating pressure also were determined. The data obtained in the investigation led to the following optimum conditions for obtaining dense $\mathrm{UO}_{2}$ by cold pressing and sintering: (1) preparing the $\mathrm{UO}_{2}$ as a submicron powder but not fine enough to be pyrophoric, (2) cold pressing at 20 to 30 tons per square inch without the use of organic binders, (3) using the following sintering schedule; (a) in $\mathrm{H}_{2}$ to $1400^{\circ} \mathrm{C}$, (b) in steam or a wet inert gas from $1400^{\circ}$ to $1599^{\circ} \mathrm{C}$, (c) in steam or a wet inert gas at $1500^{\circ} \mathrm{C}$ for a one-hour soak, and (d) cooling in $\mathrm{H}_{2}$ from $1500^{\circ} \mathrm{C}$ to room temperature. By following this procedure, pellets of $\mathrm{UO}_{2}(3 / 8-i n$. in diameter by $1 / 4$-in. high) were obtained that were 97 to $98 \%$ of theoretical density.

57

I. Amato, R. L. Colombo, and A. M. Protti, "A Comparison between Steam Sintering and Hydrogen Sintering of Uranium Dioxide Pellets," Energ. Nucl., 11 (1964) 121-128.

Steam sintering of $\mathrm{UO}_{2}$ bodies was examined mainly on technological grounds, and was compared with conventional hydrogen sintering. Though many advantages of steam sintering have been evidenced, the conclusion was reached that there is little hope that it may be a cheaper substitute for hydrogen sintering. In the course of the research work, a limited amount of basic information on the sintering mechanism was also gained.

58

D. Kolar, B. S. Brcie, B. Zatter, and V. Marinkovic, "The Influence of Atmosphere on Sintering High Surface Area Uranium Dioxide," NIJS Rpt R-50l (1967).

The influence of reducing the oxidizing atmosphere on sintering uranium dioxide powders with different specific surface areas was investigated. It was 
shown that the atmospheric influence depends on activity of $\mathrm{UO}_{2}$ powder. Combined effects of excess of oxygen in nonstoichiometric $\mathrm{UO}_{2}$ and high surface area of initial powder may limit sintered density and lead to the formation of an intergranular type of porosity. In such cases, higher densities may be achieved by sintering at lower temperatures or by sintering in hydrogen. Different observations reported by various investigators on the atmospheric influence on sintering $\mathrm{UO}_{2}$ may result from different starting materials.

\section{9}

I. Amato, R. L. Colombo, and A. M. Protti, "Sintering of $\mathrm{UO}_{2}$ in Carbon Dioxide Atmosphere," Nucl Sci. Eng., 16 (1963) 137-140.

Data are listed comparing sintering atmospheres of carbon dioxide, and dry and wet hydrogen. It was concluded that the densities achieved in carbon dioxide sintered at $1450^{\circ} \mathrm{C}$ were comparable to those obtained in hydrogen at $1700^{\circ} \mathrm{C}$.

\section{0}

N. Fuhrman, L. D. Hower, and R. B. Holden, "Low Temperature Sintering of Uranium Dioxide,"

J. Am. Ceram. Soc., 46 (1963) 114-121.

Studies of the fabrication of uranium oxide fuel pellets by the low-temperature sintering on nonstoichiometric oxide are described. Complete reversion to stoichiometric $\mathrm{UO}_{2}$ in the sintered pellets was attained by two methods: (1) sintering in a nitrogen atmosphere which contained a small amount of hydrogen, and (2) sintering in pure nitrogen and then exposing the pellets to hydrogen at the sintering temperature. Large variations in sinterability were found in commercially procured ceramic-grade $\mathrm{UO}_{2}$ powder. In studying these variations, it was discovered that fluorine was a powerful inhibitor of low-temperature sintering. This impurity could be readily removed by oxidation in air at $500^{\circ} \mathrm{C}$. The data strongly indicated that the primary mechanism responsible for the removal of residual fluorine was pyrohydrolysis. It was found that a preliminary oxidation-reduction cycle activated the less-sinterable oxides so that in every case densities of at least $95 \%$ of theoretical were obtained by sintering at $1200^{\circ} \mathrm{C}$.

61

K. Langrod, "Sintering of Uranium Oxide in the Range of 1200-1300 C," Bull. Am. Ceram. Soc., 39 (1960) 366-369.
Taking advantage of the increased sinterability of uranium oxide with an $\mathrm{O} / \mathrm{U}$ ratio of 2.30 to 1 , pellets of over $95 \%$ theoretical density were obtained after sintering at $1300^{\circ} \mathrm{C}$. The non-stoichiometric uranium oxide mixture was prepared by blending $\mathrm{UO}_{2}$ with $\mathrm{U}_{3} \mathrm{O}_{8}$. The sintered pellets were reduced to stoichiometric composition with hydrogen at a temperature of over $1200^{\circ} \mathrm{C}$. The data reported and the process described in the manufacture of the $\mathrm{UO}_{2}$ pellets are based on pilot plant production operations.

62

J. Terraza, J. Cerrolaza, and E. Aparcio, "Sintering $\mathrm{UO}_{2}$ at Medium Temperatures," Proc. 2nd Geneva Conf., Vol 6 (1968) 620-623.

Processing steps such as the effect of water additions on the density of green and sintered compacts, pressing pressure and sintering temperature were studied. Sintered pellets with an apparent density of $95 \%$ were obtained by sintering in vacuum at $1200^{\circ} \mathrm{C}$.

63

B. E. Schaner, "Metallographic Determination of the $\mathrm{UO}_{2}-\mathrm{U}_{4} \mathrm{O}_{9}$ Phase Diagram," J. Nucl. Mat., 2 (1960) $110-120$.

The $\mathrm{UO}_{2}-\mathrm{U}_{4} \mathrm{O}_{9}$ equilibrium phase diagram was established by using metallographic techniques. Data obtained from visual examination of the microstructure of annealed and quenched samples made from dense solid pieces of $\mathrm{UO}_{2}$ were used to determine the solubility of $\mathrm{U}_{4} \mathrm{O}_{9}$ in $\mathrm{UO}_{2+x}$ as a function of temperature. Two phases, $\mathrm{UO}_{2}$ and $\mathrm{U}_{4} \mathrm{O}_{9-\mathrm{y}}$, were found to exist at room temperature between $\mathrm{O} / \mathrm{U}$ ratios of 2.00 and 2.22 , although at temperatures over $940^{\circ} \mathrm{C}$ only a single phase is present. There is a wide range of $\mathrm{UO}_{2+\mathrm{x}}$ between $\mathrm{O} / \mathrm{U}$ ratios of 2.000 and 2.194 at temperatures between $200^{\circ}$ and $950^{\circ} \mathrm{C}$. In addition, a range of substoichiometric $\mathrm{U}_{4} \mathrm{O}_{9}$ lies between 2.25 and 2.20 at $940^{\circ} \mathrm{C}$ and to 2.22 at room temperature.

64

S. Aronson, R. B. Roof, and J. Belle, "Kinetic Study of the Oxidation of Uranium Dioxide," J. Chem. Phys., 27 (1957) 137-144.

Oxidation of $\mathrm{UO}_{2}$ to $\mathrm{U}_{3} \mathrm{O}_{3}$ in dry air and oxygen at temperatures of $160^{\circ}$ to $350^{\circ} \mathrm{C}$ proceeds by a twostep reaction. In the first step the tetragonal oxide of composition $\mathrm{UO}_{2.34 \pm 0.03}$ is formed. In the second step this tetragonal phase is converted to orthorhombic $\mathrm{U}_{3} \mathrm{O}_{8}$. The rate controlling process 
in the first stage is the diffusion of oxygen through uranium dioxide lattice. The value found for the diffusion coefficient $D$ is

$$
\mathrm{D}=5.5 \times 10^{-3} \exp [-(26300 \pm 1500) / \mathrm{RT}],
$$

where the activation energy is $26.3 \mathrm{kcal} / \mathrm{mole} \pm 1.5$. The second stage of the reaction proceeds by a process of nucleation and growth.

\section{5}

R. Sato, H. Doi, and H. Uchikoshi, "A Note on the Reduction of $\mathrm{U}_{3} \mathrm{O}_{3}$ to $\mathrm{UO}_{2}$," J. Nucl. Mat., 15 (1965) 146-148.

66

I. Amato, R. L. Colombo, and A. M. Protti, "On the Activation Energy of Sintering Non-Stoichiometric Uranium Oxide," J. Nucl. Mat., 11 (1964) 229-235.

Dilatometric experiments were carried out on the initial stages of sintering $\mathrm{UO}_{2} / \mathrm{U}_{3} \mathrm{O}_{8}$ mixtures of several compositions, which densified according to the diffusion-controlled mechanism first proposed by Kuczynski in 1949 .

The diffusion activation energy was of 65,800 $\mathrm{cal} / \mathrm{mol}, \pm 6200$, irrespective of $\mathrm{O} / \mathrm{U}$ ratio, and this was considered to be the diffusion activation energy of the uranium ion in the non-stoichiometric $\mathrm{UO}_{2}$ lattice.

67

R. Ram, H. S. Gadiyar, and P. K. Jena, "Kinetics of Uranium Dioxide Sintering Between $950^{\circ} \mathrm{C}$ and $1500^{\circ} \mathrm{C}$ in Dry Hydrogen Atmosphere," J. L. Comm. Met., 19 (1966) 185-189.

The kinetics of sintering of $\mathrm{UO}_{2}$ compacts prepared from ammonium diuranate and calcined at $800^{\circ} \mathrm{C}$ have been studied in the temperature range $950^{\circ}-1500^{\circ} \mathrm{C}$, in dry hydrogen atmosphere. The bulk density $\mathrm{D}_{\mathrm{s}}$ achieved at a desired period, has been determined by measuring the change in the volume of the pellets. At all temperatures studied, the bulk density and the sintering period $t$ have been related by the expression $D_{S}=C \log t+X$, where $C$ and $X$ are constants. From these results the activation energy of the process has been evaluated and the mean value has been found to be $102 \mathrm{kcal} / \mathrm{mole}$ $( \pm 10.0)$.
68

J. Belle and B. Lustman, "Properties of Uranium Dioxide," TID-7546, book 2 (1958) 442-525 (Also published as WAPD-184).

Information on the out-of-pile properties of $\mathrm{UO}_{2}$ is reviewed. Methods of preparation and characterization of $\mathrm{UO}_{2}$ powders are discussed. Results of experimental studies on the sintering process for $\mathrm{UO}_{2}$ are treated phenomenologically, and mechanisms for sintering are suggested. Results of some physical measurements made on $\mathrm{UO}_{2}$ are discussed; these include melting point, thermal conductivity, modulus of elasticity, modulus of rupture, and electrical and magnetic properties. The thermodynamic and kinetic aspects of the $\mathrm{UO}_{2} \mathrm{O}_{2}$ and $\mathrm{UO}_{2}-\mathrm{H}_{2} \mathrm{O}$ systems are examined, and measurements and interpretations of self-diffusion of uranium and oxygen in $\mathrm{UO}_{2}$ are discussed.

69

J. Belle, "Properties of Uranium Dioxide," Proc. 2nd Geneva Conf., (1958) 569-589.

70

J. Belle, Uranium Dioxide: Properties and Nuclear Applications, United States Atomic Energy Commission, U. S. Printing Office, Washington D. C., 1961.

71

H. H. Hausner and J. F. Schumar, Nuclear Fuel Elements, Chapter 13, Reinhold Publishing Corporation, New York, 1959.

72

R. B. Holden, Ceramic Fuel Elements, Chapter 3, Gordon and Breach Science Publishers, New York, 1964.

73

J. K. Dawson and R. G. Sowden, Chemical Aspects of Nuclear Reactors, Chapter 4, Butterworths \& Co., London, 1963.

74

T. Nishijima, T. Kawada, H. Kitagawa, "An Improved Process for Fabricating $\mathrm{UO}_{2}$ Pellets," J. Nuc. Matls., 16 (1965) 184-189. 
RFP-1255

$\left(\lim _{1}\right.$ 


\title{
PART II:
}

\section{MIXED URANIUM-PLUTONIUM DIOXIDES}

\author{
Alton R. Teter, Malcolm R. Harvey, and Ronald L. Leggett
}

The fabrication of mixed $(\mathrm{U}, \mathrm{Pu}) \mathrm{O}_{2}$ oxide fuel pellets described in this part had a similar objective to the $\mathrm{UO}_{2}$ program (Part I). In addition to writing a product specification and obtaining statistical information, loading studies were to be conducted with part of the pellets produced. Two compositions were required by ANL - $\left(\mathrm{U}_{.85} \mathrm{Pu}_{.15}\right) \mathrm{O}_{2-\mathrm{x}}$ and $\left(\mathrm{U}_{.70} \mathrm{Pu}_{.30}\right) \mathrm{O}_{2-\mathrm{x}}$. The substoichiometry was required because it is conveniently attainable in reducing atmospheres and the mixture is single phase at equilibrium. ${ }^{1}$

There is less literature dealing with fabrication of mixed oxides than in the $\mathrm{UO}_{2}$ system because research in breeder reactors is relatively recent. In addition the number of facilities that can work with plutonium is restricted because of the health hazard associated with the oxide. A representative list of references and abstracts dealing with fabrication and some of the problems introduced by working with the ternary system are given in Appendix B.

The problems introduced by the addition of $\mathrm{PuO}_{2}$ can be classified on how they effect fabrication and the nuclear properties of the pellets. According to several authors ${ }^{2},{ }^{3}$ fabrication is greatly influenced by the addition of $\mathrm{PuO}_{2}$ which affects the sinterability and phases present. They report significant decreases in sintered theoretical densities for $\mathrm{PuO}_{2}$ additions up to $40 \mathrm{wt} \%$. Dean, ${ }^{4}$ however reports no decrease in sintered density with $\mathrm{PuO}_{2}$ additions up to $25 \mathrm{wt} \%$.

The physical state and location of the plutonium in the fuel element is important because of nuclear requirements. In general the $\mathrm{PuO}_{2}$ has to be intimately and uniformly dispersed through out the $\mathrm{UO}_{2}$. ANL's specification states that there should be less than $0.2 \%$ of the $\mathrm{PuO}_{2}$ present in agglomerates greater than $100 \mu \mathrm{m}$ in diameter and the bulk (95\%) of it uniformly dispersed on a scale of less than $25 \mu \mathrm{m}$. This does not require the formation of complete solid solution although it is desirable.

Two general methods have been used to mix the two oxides - coprecipitation and mechanical blending. The factors that determine which method is used depends on the tightness of the product specification with respect to homogene ity. Coprecipitation involves the simultaneous precipitation of ammonium diuranate and plutonium hydroxide. If the conditions are carefully controlled a homogeneous mixture is produced which can be calcined, pressed, and sintered, under reducing conditions to high densities at temperatures between $1400^{\circ}$ and $1500^{\circ} \mathrm{C}$. X-ray diffraction results indicate complete solid solution can be obtained.

The other method, mechanical mixing, involves physically blending the oxides by wet or dry ball milling, hammermill, V-blender, etc. This process has certain advantages and disadvantages over coprecipitation. The major advantage is reduced criticality problems resulting from handling less $\mathrm{PuO}_{2}$ at the wet chemical end of the process. ${ }^{5}$ The disadvantages are slightly higher sintering temperatures to achieve the same densities and generally imcomplete solid solution formation. Some of these disadvantages are offset by appreciably reduced fabrication costs $(20 \%)$ for the mechanically blended material. ${ }^{5}$

To summarize: the addition of plut onium to $\mathrm{UO}_{2}$ powders imposes tighter restrictions on stoichiometry and introduces a new control factor of microhomogeneity in fabrication. Sintering characteristics (densification) may be affected but it would be expected that the same type of dimensional variations would be observed in fabrication as compared to $\mathrm{UO}_{2}$.

\section{EXPERIMENTAL PROCEDURE}

Two compositions were made by mechanical mixing, and fabricated according to the schematic in Figure 6. Hyperstoichiometric $\mathrm{UO}_{2}$ was obtained from Nuclear Fuel Services through ANL. Plutonium dioxide was made at Rocky Flats by calc ining oxalate $(\mathrm{Pu}+\mathrm{IV})$ at $650^{\circ} \mathrm{C}$. A list of impurities and powder characteristics for both oxides is given in Table $\mathrm{V}$. The boron and silic on analyses in the $\mathrm{PuO}_{2}$ seem very high and cannot be explained. The particle size analysis and surface area of the $\mathrm{PuO}_{2}$ are 


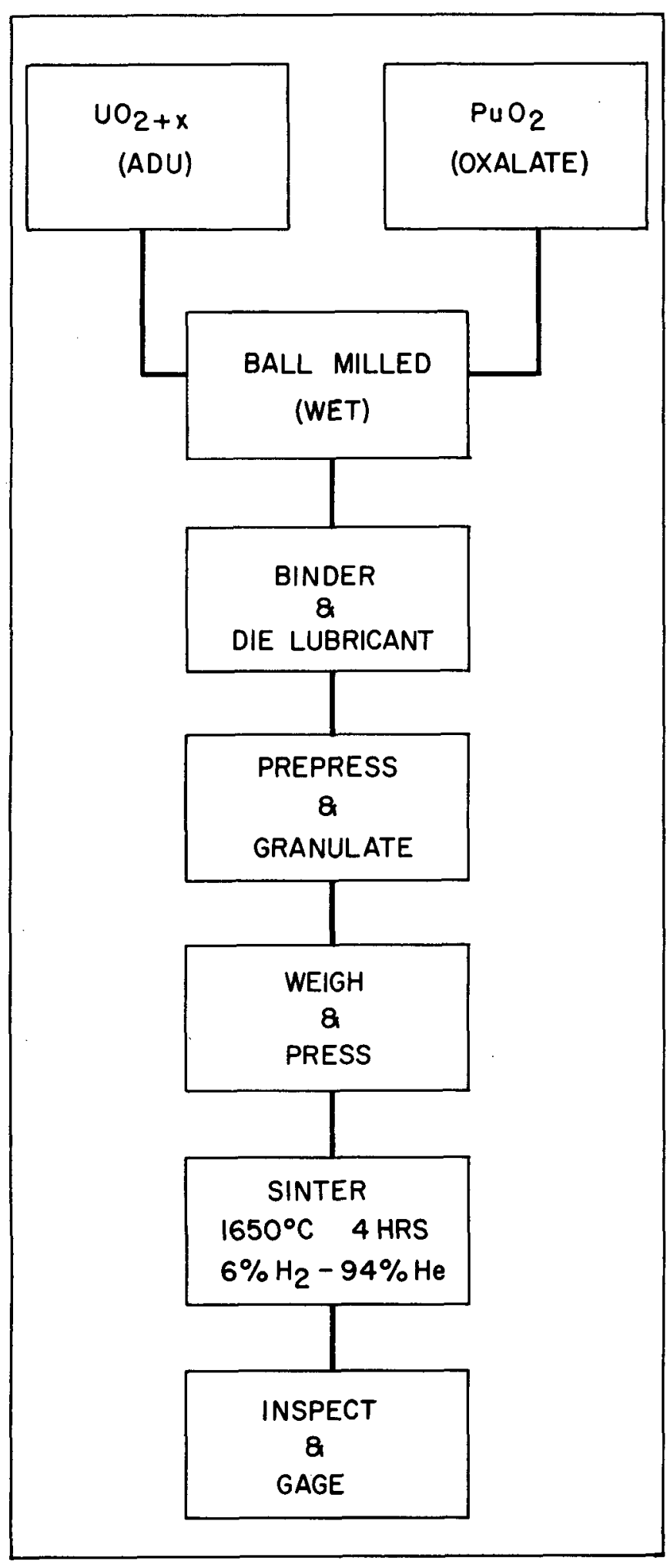

Figure 6. Schematic of fabrication used for mixed oxides.

somewhat surprising since the calcining temperature of $650^{\circ}$ should have produced a product of much
Table V. Analysis of $\mathrm{UO}_{2}$ (depleted) and $\mathrm{PuO}_{2}$.

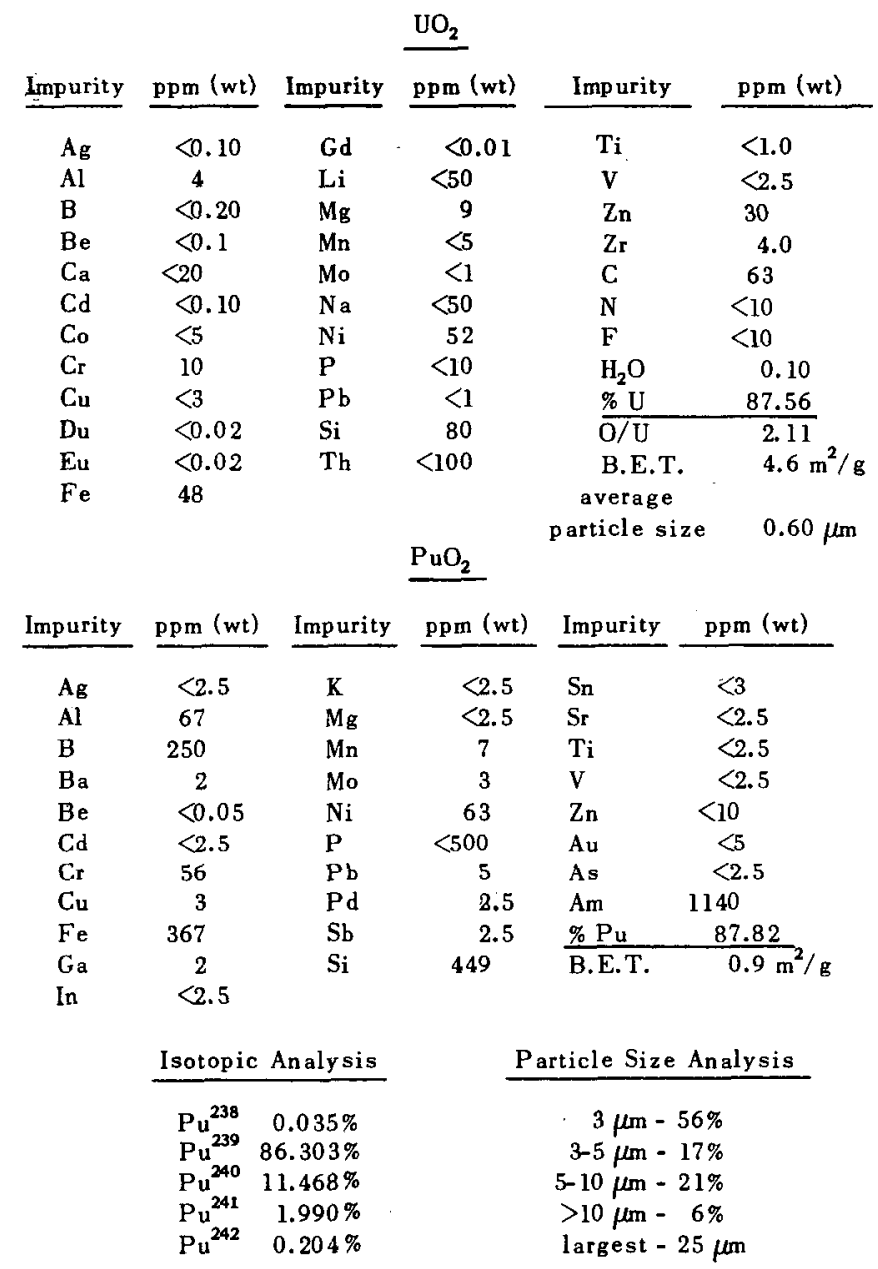

higher surface area. ${ }^{6}$ In general it is advisable to try and match surface areas of the two oxides being blended.

Because of the large $\mathrm{PuO}_{2}$ agglomerate size it was ball milled in water for 24 hours in a rubber-lined mill. Alumina balls were used as the grinding media. An equal weight of $\mathrm{UO}_{2}$ powder was then added and milled for 4 hours. Additional $\mathrm{UO}_{2}$ was added to adjust to the required composition and milled an additional 4 hours. After removal of the water, 1 wt \% carbowax 4000 and l-wt \% stearic acid were added in a $\mathrm{CCl}_{4}$ solution. After evaporation of the $\mathrm{CCl}_{4}$, the mixtures were is ostatically pressed at 10,000 psi and granulated through a 14-mesh screen. Powder for pellets of each composition was weighed to \pm 0.05 grams and pressed at various pressures between 18,000 and 40,000 psi to establish the shrinkage characteristics of the blends (Figure 7). The same press and dies were used as with the $\mathrm{UO}_{2}$ 


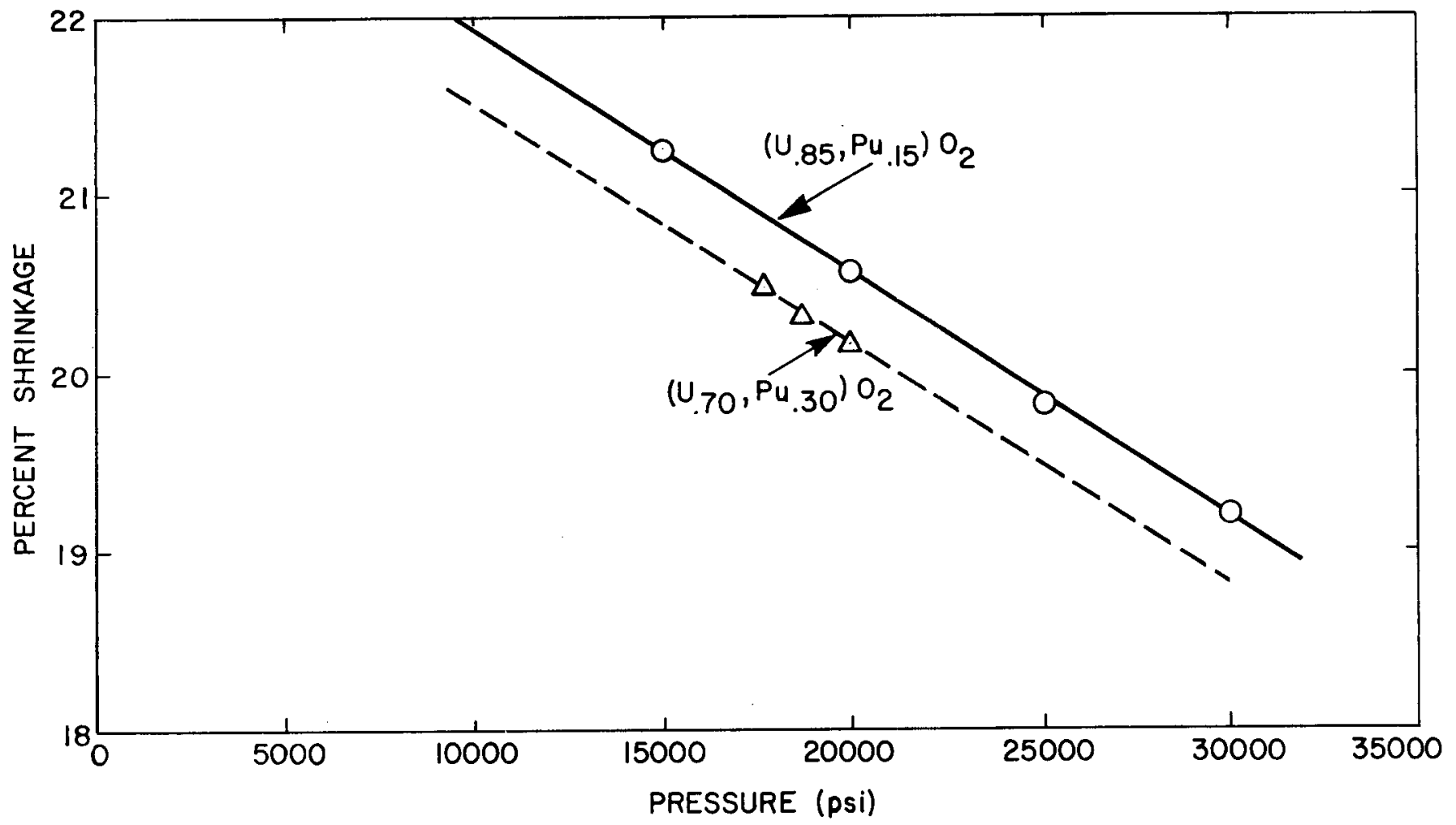

Figure 7. Shrinkage characteristics of two compositions of mixed oxides sintered at $1650^{\circ} \mathrm{C}$.

in Part I. The 15- and 30-mole percent pellets were pressed at 20,000 and 18,250 psi, respectively. A. length to diameter $(\mathrm{L} / \mathrm{D})$ ratio of 1.5 was used. Sintering was accomplished in a small graphite resistance furnace fitted with a non-porous alumina muffle tube to protect the pellets from the carbon atmosphere. Thirty-eight pellets could be fired at once in an alumina boat. Ten mesh alumina grain was used for bedding the pellets. Nominal sintering parameters were $1650^{\circ} \mathrm{C}$ for 5 hours in a dry $94 \% \mathrm{He}-6 \% \mathrm{H}_{2}$ atmosphere. A 16 hour sintering schedule was used. As with the $\mathrm{UO}_{2}$ the sintering rate had to be held to less than $100^{\circ} \mathrm{C} / \mathrm{hr}$ above $1200^{\circ} \mathrm{C}$ in order to maintain good dimensional control.

The sintered pellets were visually inspected for defects and measured at the top, waist, and bottom diameter with a blade micrometer. Five pellets from each sintering run were randomly selected for density determinations. Densities were obtained using monobromobenzene as the immersion liquid. Plutonium concentrations were determined by a calorimetric method described in Appendix C. Oxygen to metal ratios were determined by a standard oxidation-reduction cycle..$^{7}$ Homogeneity was examined with the use of an electron microanalyzer monitoring $\mathrm{Pu}-\mathrm{M} \beta$ and $\mathrm{U}-\mathrm{M} \alpha \mathrm{x}$-ray lines and standard $x$-ray diffraction techniques.

\section{RESULTS}

Tables VI, VII, and VIII give the results on hourglassing (maximum diameter - waist diameter), distortion (bottom diameter - top diameter), shrinkage and theoretical density for both compositions. The hourglass ing and distortion data are very similar to those obtained with pure $\mathrm{UO}_{2}$. The shrinkage and density reflect the different sinterability of the $\mathrm{UO}_{2}$ used in Part II. It is apparent from the data that the densities are not affected by the $\mathrm{PuO}_{2}$ concentration.

The pellets listed in Table VIII were a repeat series of those shown in Table VII which were lost in shipment to ANL as a result of severe surface spalling. A small amount of carbide must have been formed during the sintering operation. This was caused by a crack in the alumina muffle tube, which 
Table VI. Data from $296\left(\mathrm{U}_{.70} \mathrm{Pu}_{.30}\right) \mathrm{O}_{2}$ pellets fired at $1660^{\circ} \mathrm{C}$ for 5 hours.

\begin{tabular}{|c|c|c|c|c|}
\hline Run No. & $\begin{array}{l}\text { Hourglassing* } \\
\text { (in.) }\end{array}$ & $\begin{array}{l}\text { Distortion* } \\
\text { (in.) }\end{array}$ & $\begin{array}{c}\text { Shrinkage * } \\
(\%)\end{array}$ & $\begin{array}{c}\text { Theo. Dens.** } \\
(\%)\end{array}$ \\
\hline $5 / 17 / 68$ & 0.0026 & 0.0007 & 20.21 & 95.51 \\
\hline $5 / 20 / 68$ & 0.0053 & 0.0010 & 20.29 & 93.90 \\
\hline $5 / 21 / 68$ & 0.0038 & 0.0009 & 20.40 & 93.68 \\
\hline $5 / 22 / 68$ & 0.0030 & 0.0007 & 20.61 & 94.51 \\
\hline $5 / 23 / 68$ & 0.0031 & 0.0007 & 20.64 & 95.06 \\
\hline $5 / 24 / 68$ & 0.0030 & 0.0006 & 20.54 & 94.59 \\
\hline $5 / 25 / 68$ & 0.0023 & 0.0005 & 20.54 & 94.17 \\
\hline $5 / 27 / 68$ & 0.0023 & 0.0007 & 20.56 & 93.69 \\
\hline
\end{tabular}

*Averaged from all pellets in run.

**Average of 5 pellets randomly selected from each run. Overall average was $94.36 \%$. Standard deviation was $1.00 \%$.

Table VII. Data from $260\left(\mathrm{U}_{0.85} \mathrm{Pu}_{0.15}\right) \mathrm{O}_{2}$ pellets fired at $1660^{\circ} \mathrm{C}$ for 5 hours.

\begin{tabular}{|c|c|c|c|c|}
\hline Run No. & $\begin{array}{l}\text { Hourglassing* } \\
\text { (in.) } \\
\end{array}$ & $\begin{array}{l}\text { Distortion* } \\
\text { (in.) } \\
\end{array}$ & $\begin{array}{c}\text { Shrinkage* } \\
(\%)\end{array}$ & $\begin{array}{c}\text { Theo. Dens.** } \\
(\%)\end{array}$ \\
\hline $4 / 23 / 68$ & 0.0010 & 0.0004 & 20.50 & 94.04 \\
\hline $5 / 6 / 68$ & 0.0032 & 0.0007 & 20.61 & 95.11 \\
\hline $5 / 7 / 68$ & 0.0037 & 0.0006 & 20.60 & 94.86 \\
\hline $5 / 8 / 68$ & 0.0056 & 0.0006 & 20.50 & 95.41 \\
\hline $5 / 9 / 68$ & 0.0046 & 0.0007 & 20.67 & 96.11 \\
\hline $5 / 10 / 68$ & 0.0036 & 0.0008 & 20.75 & 95.84 \\
\hline $5 / 14 / 68$ & 0.0021 & 0.0007 & 20.45 & 94.42 \\
\hline $5 / 15 / 68$ & 0.0025 & 0.0007 & 20.77 & 95.64 \\
\hline
\end{tabular}

*Averaged from all pellets in run.

**Average of 5 pellets randomly selected from each run. Overall average was $95.31 \%$. Standard deviation was $0.81 \%$.

was later observed. The spalling occurred because of a water-carbide reaction between the pellets and moisture absorbed onto cotton packing material which surrounded each pellet during shipment. Runfors has observed a similar effect on $\mathrm{UO}_{2}$ sintered in a graphite tube furnace. ${ }^{8}$

Figures 8,9 , and 10 show the diametral variation for the three batches of pellets. The diameter variation is slightly larger than was observed with the $\mathrm{UO}_{2}$. This is probably because only 38 pellets could be sintered at one time and sintering conditions could not be reproduced exactly.

The increased variation in diameters represented in Figure 10 as compared to Figure 9 is evident in the shrinkages of the last three runs shown on Table VIII. A significant jump in shrinkage occurred after the gas flow had been increased a small amount over the previous runs. It appears, however, that with reasonably good process control, at least a 90 yield can be obtained on pellets with a diametral variation of less than \pm 0.002 inch.
Table VIII. Data from $240\left(\mathrm{U}_{0.85} \mathrm{Pu}_{0,15}\right) \mathrm{O}_{2}$ pellets fired at $1650^{\circ} \mathrm{C}$ for 4 hours.

\begin{tabular}{cccccc} 
Run No. & $\begin{array}{c}\text { Hourglassing* } \\
\text { (in.) }\end{array}$ & $\begin{array}{c}\text { Distortion* } \\
\text { (in.) }\end{array}$ & $\begin{array}{c}\text { Shrinkage* } \\
\text { (\%) }\end{array}$ & $\begin{array}{c}\text { Theo. Dens.** } \\
(\%)\end{array}$ \\
\cline { 1 - 1 } $6 / 17 / 68$ & 0.0049 & 0.0006 & 20.60 & \\
$6 / 18 / 68$ & 0.0031 & 0.0006 & 20.60 & 95.22 \\
$6 / 19 / 68$ & 0.0024 & 0.0004 & 20.70 & 95.00 \\
$6 / 20 / 68$ & 0.0058 & 0.0005 & 21.06 & 94.81 \\
$6 / 21 / 68$ & 0.0052 & 0.0007 & 21.12 & 95.60 \\
$6 / 22 / 68$ & 0.0035 & 0.0008 & 21.30 & 95.81 \\
\cline { 1 - 1 } & & & & &
\end{tabular}

* Averaged from all pellets in run.

**Average of 5 pellets randomly selected from each run. Overall average was $95.34 \%$. Standard deviation was $0.55 \%$.

Table IX. Oxygen to metal ratios of mixed oxides.

\begin{tabular}{|c|c|c|c|}
\hline$\% \mathrm{PuO}_{2}$ (nominal) & $\mathrm{O} / \mathrm{M}$ & wt $\% \mathrm{PuO}_{2}$ (nominal) & $\mathrm{O} / \mathrm{M}$ \\
\hline \multirow[t]{3}{*}{ 15-Sample A } & 1.965 & 30 - Sample C & 1.943 \\
\hline & 1.950 & & 1.943 \\
\hline & 1.965 & & 1.942 \\
\hline Average & 1.959 & Average & 1.943 \\
\hline \multirow{2}{*}{ 15-Sample B } & 1.921 & 30 - Sample D & 1.960 \\
\hline & 1.967 & & 1.950 \\
\hline \multirow{2}{*}{ Average } & 1.944 & & 1.945 \\
\hline & & Average & 1.952 \\
\hline
\end{tabular}

Oxygen to metal ratios were determined on a random sampling of both compositions and are listed in Table IX. Each pellet was crushed and divided into two or three parts and sampled. The averages are somewhat lower than were expected from the literature but the ratio can be easily adjusted by controlling the water vapor in the reducing gas.

The plutonium contents and impurity analyses of the two compositions are listed in Tables X and XI. The plutonium concentrations are slightly higher than expected but can be easily controlled on any production process. Aluminum, calcium, and silic on show significant concentration increases in the fabricated pellets. The aluminum contamination is expected because of the milling operation using $\mathrm{Al}_{2} \mathrm{O}_{3}$ balls . The calcium and silic on increases cannot be explained. The silic on contamination is of potential importance because of reported ${ }^{9}$ deleterious effects on densification.

Random, continuous scans of $600 \mu \mathrm{m}$ with the electron microprobe were run on both compositions to determine inhomogen eity. The scanning rate was $10 \mu \mathrm{m} / \mathrm{min}$. with a beam size of approximately $l \mu \mathrm{m}$. No variations in uranium or plutonium were seen. X-ray diffraction indicated a considerable degree of solid solution. 


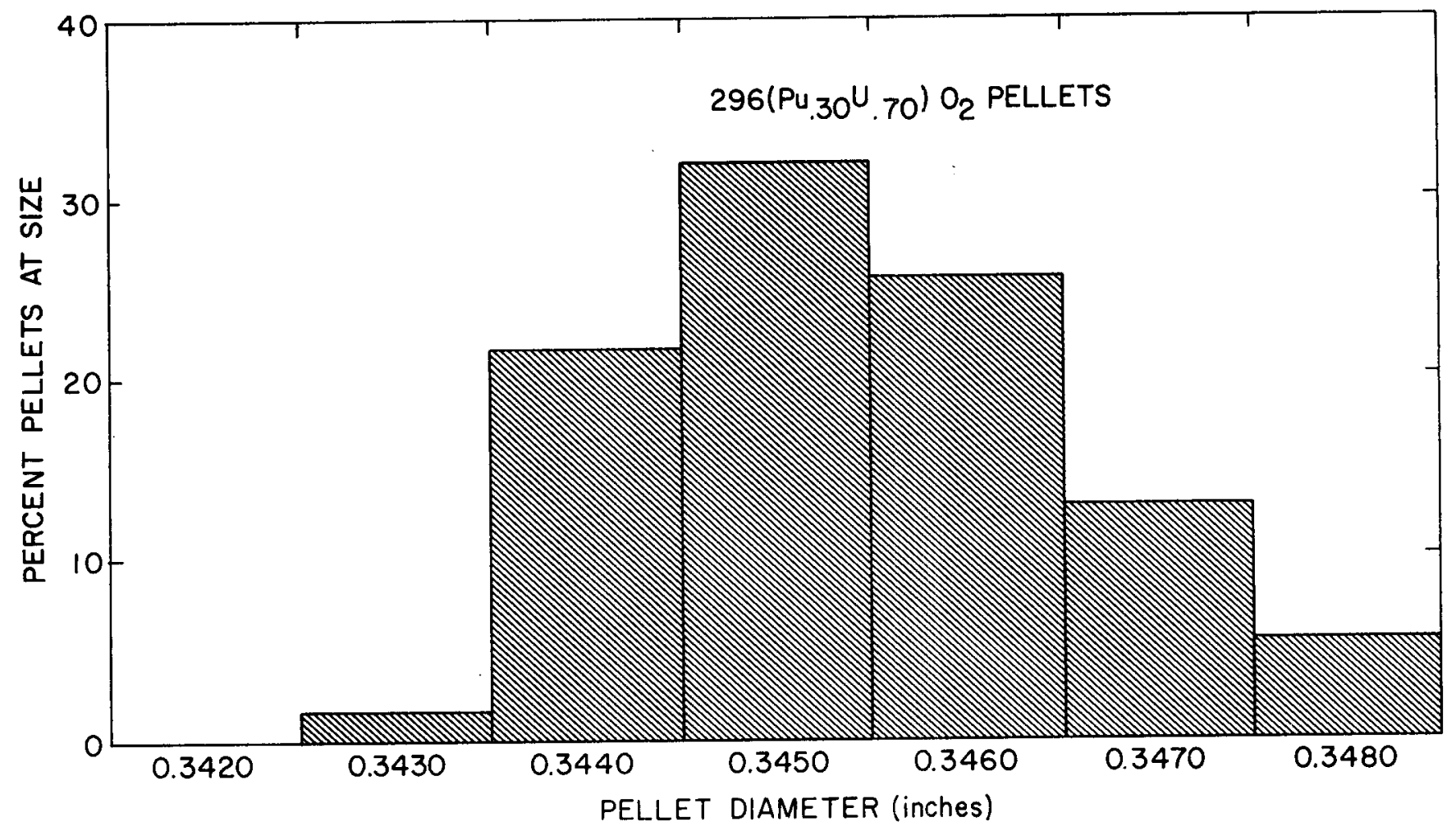

Figure 8. Histogram of pellet diameters of mixed oxides.

Figure 9. Histogram of pellet diameters of mixed oxides.

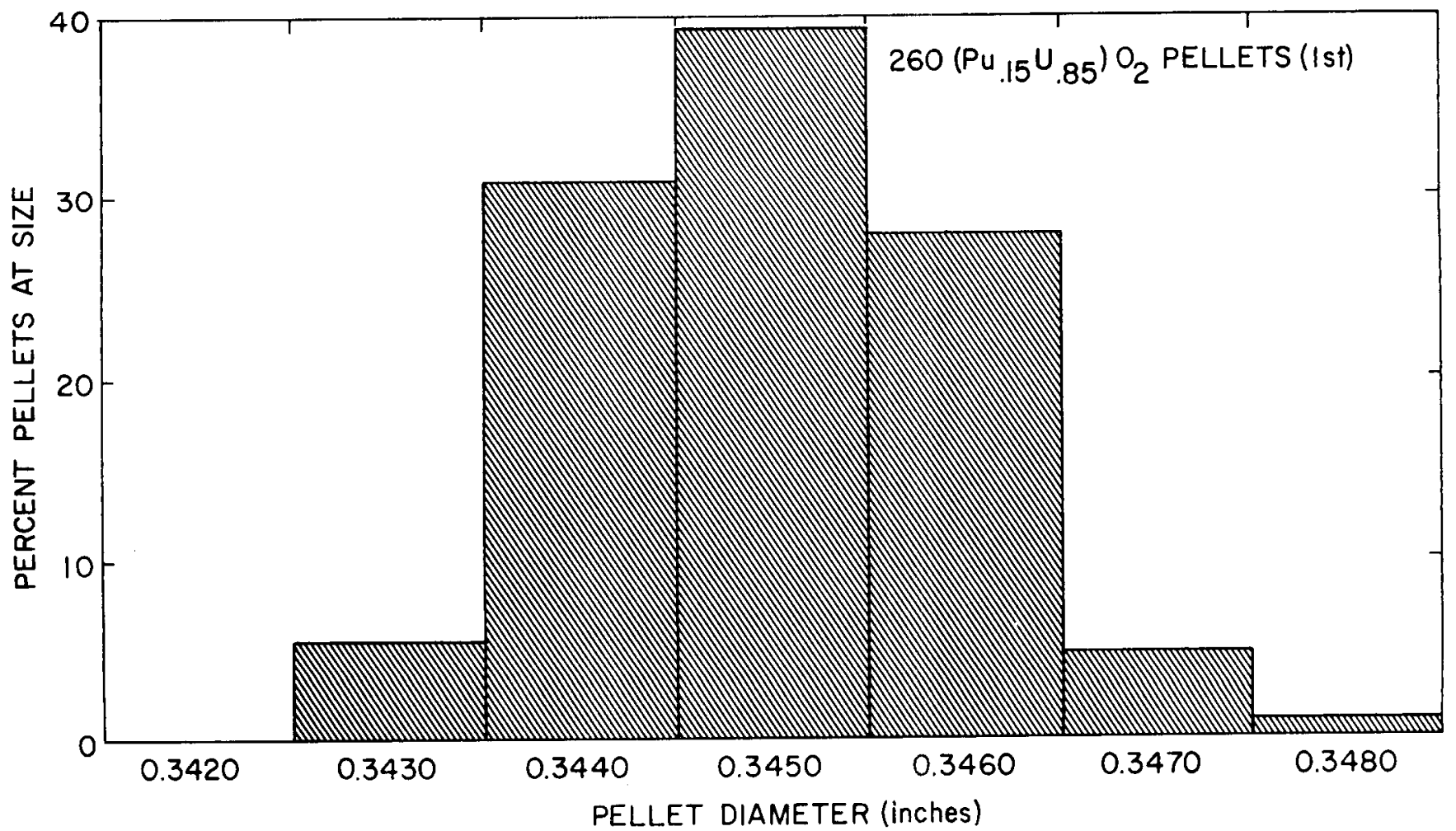




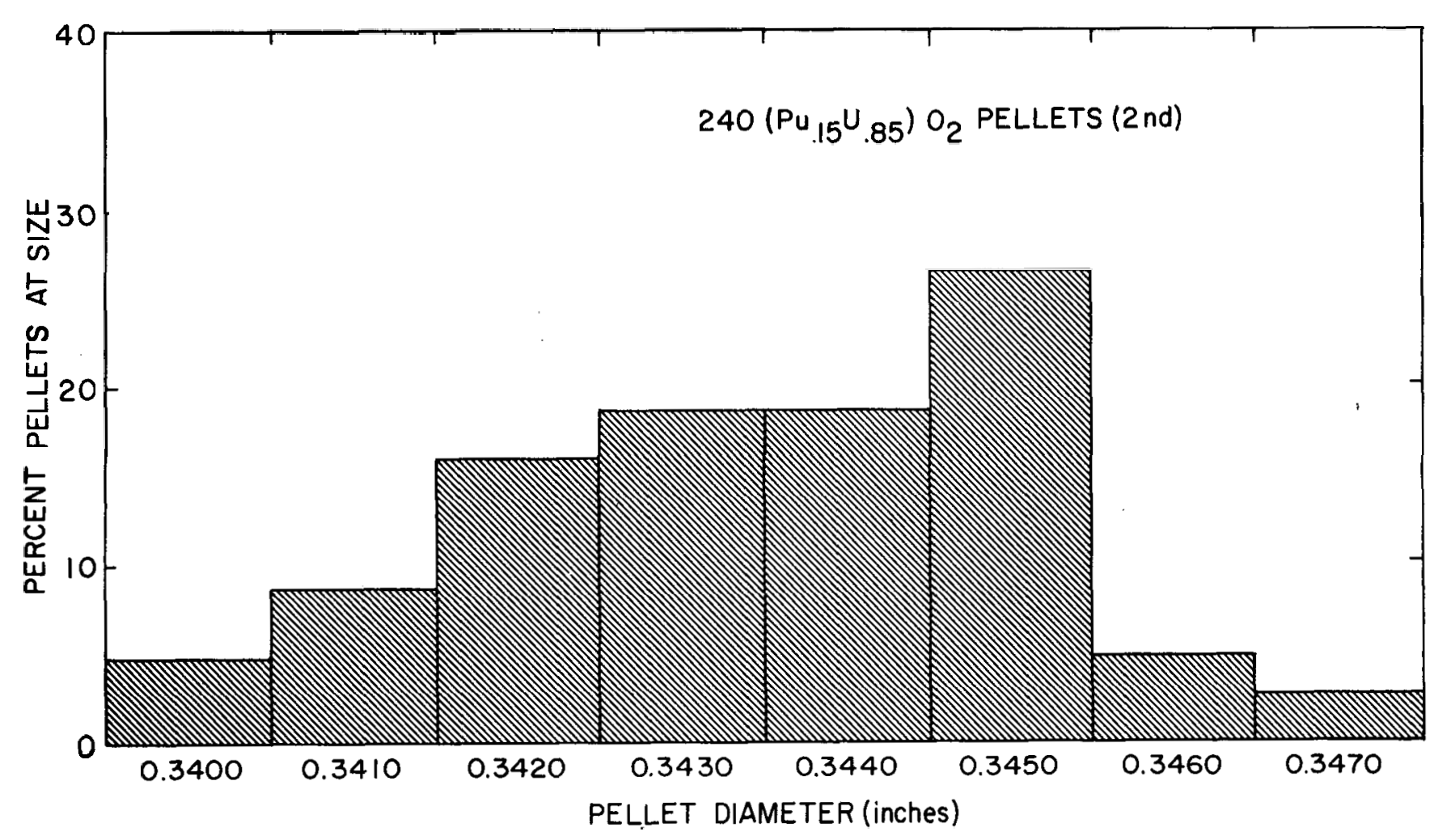

Figure 10. Histogram of pellet diameters of mixed oxides.

Table X. Impurity annalyses of mixed oxides.

\begin{tabular}{lclcl} 
& \multicolumn{4}{c}{$\left(\mathrm{U}_{.85} \mathrm{P}_{\left.\mathrm{H}_{15}\right)}\right) \mathrm{O}_{2}{ }^{*}$} \\
$\mathrm{Ag}$ & 5 & $\mathrm{Cr}$ & 50 & $\mathrm{Ni}$ \\
$\mathrm{Al}$ & 480 & $\mathrm{Cu}$ & 3 & $\mathrm{P}$ \\
$\mathrm{Au}$ & $<2.5$ & $\mathrm{Fe}$ & 95 & $\mathrm{~Pb}$ \\
$\mathrm{As}$ & $<2.5$ & $\mathrm{Ga}$ & 5 & $\mathrm{Sb}$ \\
$\mathrm{B}$ & 10 & $\mathrm{In}$ & $<2.5$ & $\mathrm{Si}$ \\
$\mathrm{Ba}$ & 10 & $\mathrm{~K}$ & 75 & $\mathrm{Sn}$ \\
$\mathrm{Bi}$ & $<0.05$ & $\mathrm{Mg}$ & $<50$ & $\mathrm{Tl}$ \\
$\mathrm{Ca}$ & $<2.5$ & $\mathrm{Mn}$ & $<2.5$ & $\mathrm{~V}$ \\
$\mathrm{Cd}$ & $<2.5$ & $\mathrm{Mo}$ & $<2.5$ & $\mathrm{Zr}$ \\
\hline
\end{tabular}

*Averaged from two determinations.

$$
\left(\mathrm{U}_{.70} \mathrm{Pu}_{.30}\right) \mathrm{O}_{2}{ }^{*}
$$

$\begin{array}{lccccc}\mathrm{Ag} & <2.5 & \mathrm{Cu} & 1 & \mathrm{Pd} & <2.5 \\ \mathrm{Al} & 375 & \mathrm{Fe} & 180 & \mathrm{Sb} & <2.5 \\ \mathrm{As} & <2.5 & \mathrm{Ga} & 20 & \mathrm{Si} & >400 \\ \mathrm{Au} & <2.5 & \mathrm{In} & <2.5 & \mathrm{Sn} & 10 \\ \mathrm{~B} & 22 & \mathrm{~K} & <2.5 & \mathrm{Sr} & <2.5 \\ \mathrm{Ba} & 10 & \mathrm{Mg} & 5 & \mathrm{Ti} & 10 \\ \mathrm{Be} & 0.1 & \mathrm{Mn} & <0.5 & \mathrm{~V} & <2.5 \\ \mathrm{Ca} & 250 & \mathrm{Mo} & 5 & \mathrm{Zn} & 10 \\ \mathrm{Cd} & <2.5 & \mathrm{Ni} & 120 & \mathrm{P} & <500 \\ \mathrm{Cr} & 29 & \mathrm{~Pb} & <2.5 & & \end{array}$

*Averaged from two determinations.
Table XI. Plutonium concentration of mixed oxides.

$\mathrm{Pu}(0.1336$ Nominal $)(\mathrm{g} / \mathrm{g})$

$P u(0.2666$ Nominal $)(\mathrm{g} / \mathrm{g})$
$0.1364^{*}$
0.1377
0.1373
0.1374

0.2747

*Two samplings were taken from each pellet. Estimated error is $\pm 0.3 \%$ of amount present.

\section{DISCUSSION}

The results of this work and an analysis of the literature survey indicate that there should not be any problem in fabricating pellets to close dimensional tolerances without grinding. In addition to results obtained here there are a number of references to fabrication without grinding.

Bataller, et. al. ${ }^{10}$ reports the fabrication of $320 \mathrm{~kg}$ of mixed oxide into pellets with an $84 \%$ yield of diameters varying less than \pm 0.002 inch. Mattys ${ }^{11}$ fabricated 7000 mixed oxide pellets within tolerances 
of less than $\pm 0.03 \mathrm{~mm}(\sim 0.001$ in. $)$. Overall losses were 12 percent. Craig, et. al., ${ }^{12}$ reports that diametral variations on SEFOR sized pellets $(\sim 1.0$ in. diameter by $1 / 2$-in. length) can be controlled to give an $85 \%$ yield within \pm 0.005 in. of the nominal diameter.

Although results reported here are insufficient, the literature indicates that there is little problem in controlling the $\mathrm{O} /(\mathrm{U}+\mathrm{Pu})$ ratio and the plutonium concentration. Bataller, et. al., ${ }^{10}$ reports a mean $\mathrm{O} /(\mathrm{U}+\mathrm{Pu})$ ratio of 1.985 with a standard deviation of 0.005 . Their mean plutonium concentration was 22.95 wt \% with a standard deviation of 0.11 wt \%. Caldwell ${ }^{9}$ states that the standard deviation on $\mathrm{O} /(\mathrm{U}+\mathrm{Pu})$ ratio was $0.012-$ and $0.04-$ wt $\% \mathrm{Pu}$ on thirteen production lots of nominal $6.6 \mathrm{wt} \%$ $\mathrm{PuO}_{2}-\mathrm{UO}_{2}$ pellets.

Microhomogeneity of mechanically mixed pellets continues to be a potential problem. This is primarily caused by poorly defined specifications on how much and what kind of inhomogeneity can be tolerated. Techniques such as autoradiography and electron microanalys is can readily detect inhomogeneities on a level within the tightest specifications. Autoradiography in particular is well suited to detection of areas $(>25 \mu \mathrm{m})$ of high $\mathrm{PuO}_{2}$ concentration because the method samples the entire exposed surface. Microanalys is is severly limited in this case because of the sampling required to obtain statistically significant data.

\section{REFERENCES}

1. C. S. Caldwell and K. H. Puechl, "Plut oniumUranium Dioxide Powder and Pellet Fuel Manufacture," Nuclear Metallurgy, Vol 13, AIME (1968) 174-194.

2. T. D. Chikalla, "Studies on the Oxides of Plutonium," Plutonium 1960, Cleaver-Hume Press, London (1961) 455-485.
3. L. E. Russel, et. al., "Observations on Phase Equilibria and Sintering Behavior in the $\mathrm{PuO}_{2}$ $\mathrm{UO}_{2}$ system," J. Nucl. Mat., 5 (1962) 216-227.

4. G. Dean, et. al., "Sintering of (U,Pu)O $\mathrm{O}_{2}$ Pellets," CEA-R-2737 or EURFNR 96.F (1965).

5. A. Biancheria and R. J. Allio, "Fabricating $\mathrm{PuO}_{2}-\mathrm{UO}_{2}$ Fuels: How Leading Processes Compare," Nucleonics, 23 (1965) 46-50.

6. J. L. Stakebake, Private communication, Rocky Flats Division, The Dow Chemical Company, Golden, Colorado.

7. W. L. Lyon, "The Measurement of Oxygen to Metal Ratio in Solid Solutions of Uranium and Plutonium Dioxides," GEAP-4271 (1963).

8. U. Runfors and R. Kiessling, "Sintering of Uranium Dioxide," TID-7546 Book 2 (1958) 402-413.

9. C. S. Caldwell and I. D. Thomas, "Plutonium Uranium Mixed Oxide Preparation and Fabrication Experience,"'Nucl. Eng. Part IVIII, 63, (1966) 147-155.

10. S. Bataller, et. al., "Mixed Uranium-Plutonium Oxide Fuel Fabrication for Rhapsodie," Nuclear Metallurgy, Vol 13, AIME (1968) 231-241.

11. H. M. Mattys, "Plutonium Metallic and Ceramic Fuel Fabrication and Development at the European Institute for Transuranium Elements," Nuclear Metallurgy, Vol. 13, AIME (1968) 279-292.

12. C. N. Craig, C. M. Myer, and M. L. Thompson, "Plutonium-Uranium Mixed Oxide Fuel Pellet Fabrication Development for the Southwest Experimental Fast Oxide Reactor," GEAP-5285 (1966). 
RFP-1255
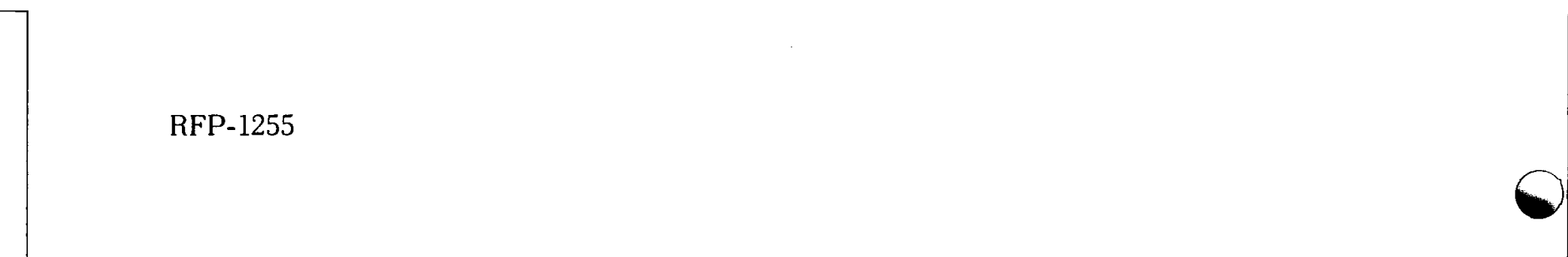

(1)

(2)

.

(2)

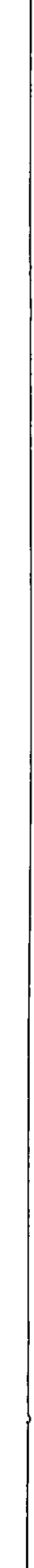

$$
\text { (1) }
$$

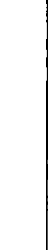

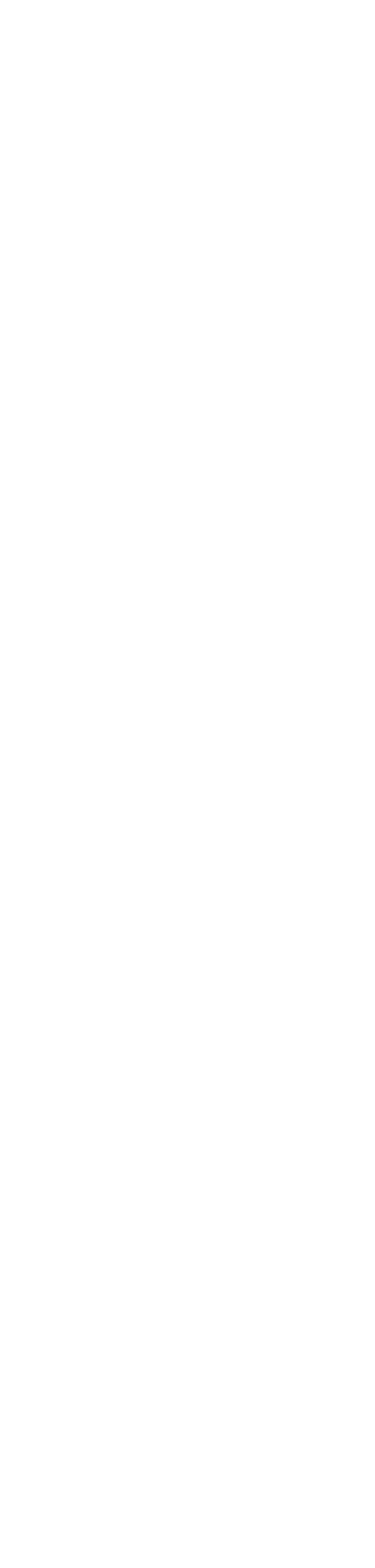




\section{Appendix B: Literature Survey of Fabrication of Mixed Oxides.}

The following is a relatively complete list of references and abstracts dealing with the fabrication of mixed $\left(\mathrm{U}, \mathrm{Pu}_{\mathrm{u}} \mathrm{O}_{2}\right.$ fuel elements. References on other subjects unique to the mixed oxide system such as thermodynamics, homogeneity, etc., are als o included.

\section{1}

A. Biancheria and R. J. Allio, "Fabricating $\mathrm{PuO}_{2}$ $\mathrm{UO}_{2}$ Fuels: How Leading Processes Compare," Nucleonics, 23 (1965) 46-50.

2

C. S. Caldwell and 1. D. Thomas, "Plutonium Uranium Mixed Oxide Preparation and Fabrication Experience," Nucl. Eng. Part XVIIl, 63 (1966) 147-155.

3

C. S. Caldwell and K. H. Puechl, "PlutoniumUranium Dioxide Powder and Pellet Fuel Manufacture," Nuclear Metallurgy, Vol. 13, AIME (1968) 174-194.

Plutonium-uranium dioxide powder preparation and pellet fuel manufacturing methods have been developed to meet increasing demands for critical assembly, test reactor and demonstration power react or fuel elements. This paper reviews current conversion and fabrication processes and discusses techniques for control of mixed-oxide pellet characteristics including plutonium microhomogeneity and oxygen/metal ratio. Experience gained during fabrication of thermal recycle and fast breeder type $\mathrm{PuO}_{2}-\mathrm{UO}_{2}$ fuel materials in quantities up to $500 \mathrm{~kg}$ is presented. Product variability data are included.

\section{4}

A. J. Simpson, "Processing Nuclear Fuels," Ceram. Age., (1967) 50-54.

5

A. Bel, "Frittage d'Oxyde d'Uranium et de Plutonium," Plutonium 1960, Cleaver-Hume Press, Lond on (1961) 449-455.

Experiments have been made to study the influence on sintering of plutonium oxides and mixed plutonium and uranium oxides, of the method of preparation (coprecipitation or physical mixing, starting material), of the sintering temperature, and of the specific surface area of the oxide.

The behavior of these oxides has been shown to be similar to that of pure uranium oxide and the use of large specific surface area powders for preparing oxide mixtures has been emphasized when good homogeneity of the sintered products is required.

6 G. Dean, et. al., "Sintering of $(\mathrm{U}, \mathrm{Pu}) \mathrm{O}_{2}$ Pellets," CEA-R-2737 or EURFNR 96.F (1965).

7

"Manufacture of Mixed Uranium and Plutonium Oxide Pellets by Sintering," NP-TR-1233.

\section{8}

S. Bataller, et. al., "Mixed Uranium-Plutonium Oxide Fuel Fabrication for Rhapsodie," Nuclear Metallurgy, Vol. 13, AIME (1968) 231-241.

The fabrication of the 96 first elements for the Rapsodie reactor has been carried out at the Atelier de Technologie du Plutonium in 1965-1966. It represents the use of $320 \mathrm{~kg}$ of mixed oxide $(\mathrm{U}, \mathrm{Pu}) \mathrm{O}_{2}$ containing about $70 \mathrm{~kg}$ of plut onium. First the fabrication is examined, and the total evaluation of the fabrication and the yield of the different stages are detailed. Then the problems and difficulties raised by the fabrication are studied. There is a summary, as an extension, of the studies devoted to the adjustments of the procedure for the fabrication of low density oxide for Rapsodie. The specifications considered for the first charge pellets of the Phenix reactor are given.

9

A. T. Jeffs, R. R. Boncher and L. R. Norlock, "Fabrication of $\mathrm{UO}_{2}-\mathrm{PuO}_{2}$ and $\mathrm{ThO}_{2} \mathrm{PuO}_{2}$ Experimental Fuel," AECL-2675 (1967).

Fabrication procedures are described for the preparation of an experimental charge of eleven sintered pellet fuel elements for a pressurized water test loop 
in the NRX reactor. Six elements of mechanically mixed $\mathrm{UO}_{2}-\mathrm{PuO}_{2}$ plus two enriched $\mathrm{UO}_{2}$ reference elements were fabricated by two alternative routes to permit comparison of performance during operation. The two alternative processes were conventional hydrogen sintering at $1600^{\circ} \mathrm{C}$ and a low temperature route starting with hyperstoichiometric mixed oxides and using Ar- $10 \% \mathrm{H}_{2}$ as the reducing atmos phere.

Three elements containing mechanically mixed $\mathrm{ThO}_{2}$ $\mathrm{PuO}_{2}$ were fabricated by a conventional high temperature sintering route to an average pellet density of $9.6 \mathrm{~g} / \mathrm{cm}^{-3}$.

Plutonium dioxide contents for these elements ranged up to $1.93 \mathrm{wt} \%$ and all elements were of fuel length $15 \mathrm{~cm}$, clad in Zircaloy-2 of $2.03 \mathrm{~cm}$ outside diameter.

10

J. M. Cleveland, et. al., "Fast Oxide Breeder Project: I Fuel Fabrication, II Preliminary Sintering Studies of Plutonium-Uranium Dioxide Pellets," GEAP-3486, 3487 (1960).

Forty mixed oxide (20 percent plut onium dioxide40 percent uranium- 235 dioxide -40 percent uranium-238 dioxide) fuel specimens were fabricated for irradiation testing in the General Electric Test Reactor (GETR).

The material for these specimens was prepared by mixing nitrate solutions of the three is otopes in the proper ratio and precipitating with ammonium hydroxide. After drying, the precipitate was reduced to oxide in a hydrogen-nitrogen atmosphere at $900^{\circ} \mathrm{C}$.

Finely ground powder was pressed into pellets at 43,200 pounds per square inch pressure and sintered, generally for 4 hours, in a heliumhydrogen atmosphere at $1600^{\circ}-1700^{\circ} \mathrm{C}$. The resulting pellets had lengths of about 0.250 inches, diameters of 0.149 inches, and generally, densities approximately 95 percent of theoretical. These pellets were used in 22 of the 40 specimens.

Eighteen specimens were fabricated by swaging. The powder for these specimens was high-fired at $1350^{\circ}-1400^{\circ} \mathrm{C}$ in hydrogen-helium to achieve a bulk density of 40-50 percent of the oretical. Swaged density was 75 percent.
The time required to fabricate the pelleted specimens was approximately twice that required for the swaged specimens.

A series of brief studies was made in which the effects of various parameters on sintering efficiency of plutonium dioxide-uranium dioxide pellets were noted. Single-pressing produced pellets equal in sintered density to those pressed twice. The effect of particle size in the range above 40 microns on sintered densities seems to be minor. A minimum temperature in excess of $1500^{\circ} \mathrm{C}$ is necessary for effective sintering, and a hydrogen-helium atmosphere yields better results than pure helium. A technique was developed for determining pellet densities while sintering, and yielded infomation which reveals that the greater part of densification occurs during the first few minutes of sintering.

11

C. N. Craig, C. M. Myer and M. L. Thompson, "Plutonium-Uranium Mixed Oxide Fuel Pellet Fabrication Development for the Southwest Experimental Fast Oxide Reactor," GEAP-5285 (1966). A process was developed to fabricate SEFOR-design plutonium-uranium oxide pellets with densities $85 \%$ to $96 \%$ of theoretical. Geometric defects, such as end-dishing and hour-glassing typical of pellets fabricated by conventional methods, were minimized or eliminated through a prepressing step in powder preparation. The pellet quality was ascertained by uniform $\mathrm{O} / \mathrm{M}$ ratio and density measurements made as a function of radius, as well as by final chemical analys is. The process was also used successfully to fabricate pellets with dished ends of controlled geometry.

12

H. M. Mattys, "Plutonium Metallic and Ceramic Fuel Fabrication and Development at the European Institute for Transuranium Elements," Nuclear Metallurgy, Vol 13, AIME (1968) 279-292.

Some aspects of our work in the field of plutonium fuel fabrication and development are reported.

About 2,100 uranium-plutonium-iron alloy fuel rods have been produced for the critical experiment MASURCA by a centrifugal casting method. The total amount of plutonium contained in this loading was $175 \mathrm{~kg}$. 
About 7,000 uranium - plutonium oxide pellets have been sintered for our fast reactor irradiation program. Dry powder blending was preferred to coprecipitation. No centerless gringing was necessary to obtain reproducible pellet diameter $(5.40 \mathrm{~mm} \pm 0.03 \mathrm{~mm})$. The stoichiometry of our pellets was adjusted by sintering atmosphere control.

Spherical particles of $\mathrm{PuO}_{1.62}$ have been produced to be irradiated as graphite coated particles.

13

J. M. Leblanc and R. Horne, "Belgian Experience in Fabrication and Irradiation Performance of Fast Reactor Fuel $\left(\mathrm{UO}_{2}-\mathrm{PuO}_{2}\right)$," Nuclear Metallurgy, Vol. 13, AIME (1968) 418-438.

The paper gives a description of the fast reactor fuel development program. Three types of fuel pins are developed: conventional pelleted fuel pins, collapsed clad fuel pins and vibratory compacted fuel pins. The specifications of the three types of fuel pins and the fabrication flowsheets are given. Parameters related to low density fabrication are discussed.

Irradiation tests on fast reactor fuel pins will be achieved in the Enrico Fermi fast reactor, the Dounreay fast reactor and the BR2 reactor. The paper gives the irradiation parameters which have to be evaluated.

14

N. H. Brett, J. D. L. Harrison and L. E. Russell, "The Production of $\mathrm{PuO}_{2}-\mathrm{UO}_{2}$ Irradiation Pellets," Plutonium 1960, Cleaver-Hume Press, London (1961) 430-448.

The development of a process for preparing dense un if orm pellets of $\mathrm{PuO}_{2}-\mathrm{UO}_{2}$ is described. Details are included of equipment construction, the effects of various parameters on sintered density and of some properties of the final pellets.

15

T. D. Chikalla, "Studies on the Oxides of Plutonium," Plut onium 1960, Cleaver-Hume Press, London (1961) 455-485.

In support of the Plutonium Recycle Program at Hanford, the properties of $\mathrm{PuO}_{2}$ are be ing investigated. This paper reports sintering studies on $\mathrm{PuO}_{2}$ and $\mathrm{PuO}_{2}-\mathrm{UO}_{2}$ mixtures and solid solutions; melting studies on $\mathrm{PuO}_{2}$ and $\mathrm{UO}_{2}$; thermal expansion data to $1000^{\circ} \mathrm{C}$; and irradiation data on $\mathrm{PuO}_{2}$ $\mathrm{UO}_{2}$ mixtures.

The existence of a continuous series of solid solutions formed during sintering has been established for the system $\mathrm{UO}_{2}-\mathrm{PuO}_{2}$. A linear relation between lattice parameter and composition exists. Extensive sinterability data on the isomorphous compounds $\mathrm{UO}_{2}$ and $\mathrm{PuO}_{2}$ and the ir intermediate compositions has been obtained. The effect on sintered density of temperature, time, and concentration for both physical additions of $\mathrm{PuO}_{2}$ and additions of $\mathrm{UO}_{2}-\mathrm{PuO}_{2}$ solid solutions to $\mathrm{UO}_{2}$ have been studied. Evaluation data are supported by microscopic examination and $x$-ray diffraction.

Melting point studies have been performed on $\mathrm{PuO}_{2}$, $\mathrm{UO}_{2}$ and solid solutions of the two compounds, and the liquidus for the system has been obtained. Thermal expansion coefficients for $\mathrm{PuO}_{2}$ and $\mathrm{UO}_{2}$ have been obtained to temperatures on the order of $1000^{\circ} \mathrm{C}$.

Irradiation tests performed on a number of specimens of both high and low density of $\mathrm{UO}_{2}-\mathrm{PuO}_{2}$ are presented. Concentrations up to $7.5 \mathrm{wt} \% \mathrm{PuO}_{2}$ in $\mathrm{UO}_{2}$ are under study. A comparison of the preand post-irradiated structures is made.

16

J. D. L. Harris on, E. Foster, and L. E. Russell, "The Sintering Behavior of Mixed $\mathrm{UO}_{2}$ and $\mathrm{PuO}_{2}$ Powders,"' Plans. Proc. 1961, Metallwerk Plansee AG., Reutte/Tyrol 1962, 140-165.

This report gives an account of investigations into the sintering behavior of mechanically mixed $\mathrm{PuO}_{2}$ and $\mathrm{UO}_{2}$ in the composition range from 0 to $25 \%$ $\mathrm{PuO}_{2}$. The density, oxygen-to-metal ratio and the degree of solid solution attained have been measured and correlated with the experimental variables. The variables were: $\mathrm{Pu} / \mathrm{U}$ ratio, sintering atmosphere, sintering temperature, sintering time, compacting pressure, amount of binder added to powders, method of preparation of $\mathrm{PuO}_{2}$ and ball-milling of the mixed powders prior to pressing.

17

I. LaFontaine and E. Vanden Bemden, "Sintering of $\mathrm{UO}_{2}-\mathrm{PuO}_{2}$ mixtures," Plansee Proceedings 1961, Metallwerk Plansee AG., Reutte/Tyrol (1962) 160-165. 
18

G. Muhling, W. Stoll, and R. Theisen,

"Plutoniumverteiung in Geschnolzenen (U, $\mathrm{Pu}_{\mathrm{u}} \mathrm{O}_{2}$

Kernbrennstoffen," J. Nucl Mat., 24 (1967) 523-527.

The mixed oxide of plutonium and uranium can be melted by a method developed for pure uranium dioxide, involving direct current heating under inert gas on a technologically useful scale. The solid solution thus produced is homogene ous at least to the resolution limit of the method of investigation used, i.e., $1 \mu \mathrm{m}$. The melting technique may therefore come to be of considerable importance for the production of very dense oxide starting material, and therefore for the production of nuclear fuels by the vibratory process.

19

A. G. Adwick and E. R. Batchelor, "Influence of Powder Heat Treatment on the Sintering of (UPu) ${ }_{2}$," Plutonium 1965, Chapman and Hall, London (1967) 623-638.

A series of $(\mathrm{UPu}) \mathrm{O}_{2}$ powders was prepared with surface area values between 2 and $32 \mathrm{~m}^{2}-\mathrm{g}$ by variation of the heat treatment conditions in either hydrogen or carbon dioxide. An equivalent surface area was obtained at lower temperatures in carbon dioxide than in hydrogen. These powders were compacted and sintered. The data are discussed. in relation to re-arrangements within particles, aggregation of crystallites and sintering of particles. If the heat treatment temperatures do not greatly exceed that at which sintering commences, variations in pressed density do not affect the sintered density. Powder aggregation however, as indicated by the tap and pressed density, was found to exert a resistance to consolidation and cause the dependence of sintered density on pressing pressure.

20

A. G. Adwick and W. S. C. Reilly, "The Role of Oxygen/Metal Ratio during the Sintering and Oxidation of Some Uranium-Plut onium Oxides," Science of Ceramics, Academic Press, London (1967) 215-235.

Concerns non-stoichiometry in co-precipitated U-rich solid solutions and its influence on sinterability, theoretical density and the ox idation behavior. Powders with initial oxygen/metal ratios between 2.00 and 2.46 were sintered in argon and in hydrogen. Density data show that the behavior in argon of $(\mathrm{U}, \mathrm{Pu}) \mathrm{O}_{2+\mathrm{x}}$ is similar to $\mathrm{UO}_{2+\mathrm{x}}$. In hydrogen, however, the near-stoichiometric compositions ultimately yield the highest densities. The oxygen/metal ratio effects may be explained either by the low-temperature formation of large closed pores or by the enhanced sinterability of sub-stoichiometric oxide. Oxygen from unreduced precipitate has a more deleterious effect on density than interstitial oxygen introduced by oxidation of fully reduced oxide. Plots of lattice parameter against oxygen/metal ratio tend to deviate positively from the theoretical relationship.

Sintered-pellet oxygen/metal ratios (1.92-2.10) did not change during six months' exposure to air at room temperature. At $100^{\circ} \mathrm{C}$ there was a gradual conversion of the sub-stoichiometric pellets to stoichiometric compositions. Oxidation/temperature curves have been determined by thermobalance.

21

R. G. Sowden, R. Ainsley, and G. N. Stockdale, "The Preparation of $\mathrm{UO}_{2} \cdot \mathrm{PuO}_{2}$ Powders for Nuclear Fue ls," Prog. Nucl. Energ. Series 4, Vol. 5 (1963) 347-370.

Work carried out on the preparation of $\mathrm{UO}_{2} \cdot \mathrm{PuO}_{2}$ powders by way of co-precipitation from mixed nitrate solutions is described. Continuous coprecipitation with ammonia from $\mathrm{U}(\mathrm{VI}) \mathrm{Pu}$ (IV) solution constitutes a versatile method of preparing powders which sinter to a high density, but these ADU-type precipitates have poor handling properties. Alternative techniques are surveyed, particularly in relation to plutonium contents of 15 per cent and higher: co-precipitation with oxalic acid from $\mathrm{U}(\mathrm{IV}) \mathrm{Pu}(\mathrm{III})$ solution energies as the most attractive alternative process.

22

K. H. Puechl, "Plutonium Fuel Development Programs at NUMEC," HW-75007 (1962) 9.1-9.19.

23

M. R. H. Hill and C. E. Mellish, "Determination of the Micro-Homogeneity of $\mathrm{UO}_{2} / \mathrm{PuO}_{2}$ Sintered Fuel Pellets by Autoradiography," J. Nucl Mat., 16 (1965) 155-161.

The microhomogeneity of $\mathrm{UO}_{2} / \mathrm{PuO}_{2}$ sintered fuel pellets has been determined autoradiographically from data obtained from the "stars" produced by high local concentrations of $\mathrm{PuO}_{2}$. The method 
involved the counting of the alpha tracks, in "stars," of projected length greater than a certain fraction, $x$, of the maximum track length, $R_{e}$, in the emulsion. The value of $x$ chosen, $0.4 R_{e}$, limits the depth of the section being examined and is a compromise between obtaining the thin section required by the method used in interpreting the results, and obtaining a reasonable number of tracks. The number of tracks, of length $\times \geqslant 0.4 R_{e}$, associated with particular "stars" is used to calculate the volume of $\mathrm{PuO}_{2}$ in the sectioned particles and the true particle size distribution in the fuel calculated from the size distribution of the sectioned particles in the plane of observation.

Oxide type fuels containing both uranium and plutonium have been proposed as fuels for fast reactor systems. At the UKAEA Establishment at

Dounreay a study is being made of the use of solid solutions of plutonium and uranium dioxides in such a system. In the investigations, which are being made into the manufacture and behavior of these fuels, one of the factors which is of prime interest is the oxygen-to-metal ratio of the solid solution.

In the uranium dioxide-plutonium dioxide system a continuous solid solution is formed which has a fluorite type lattice and is isostructural with both of the dioxide compounds. This solid solution can contain either an excess of a deficiency of oxygen and thus depart from the overall stoichiometry of an oxygen-to-metal atomic ratio of 2.000 while still remaining a single-phase system exhibiting a cubic structure. Methods of measuring the stoichiometry of the solid solution which have been investigated include: (a) the measurement of the carbon dioxide formed on the reduction of the super stoichiometric oxide to $\mathrm{MO}_{2}$ with carbon monoxide, (b) the gravimetric determination of the composition of the uranium-plutonium dioxide by ignition, in air, to a known composition, (c) the use of hydrogen and oxygen redox cycles on a thermobalance, and (d) the use of $x$-ray diffraction techniques.

Work on the reduction of the superstoichiometric solid solution with carbon monoxide failed to yield a satisfactory analytical method for determining the excess of oxygen. This approach has the further limitation that it cannot be applied to substoichiometric oxides.

Studies of the oxidized solid solution of plutoniumuranium dioxide has shown that it is extremely difficult to control and reproduce the oxygen-tometal ratio of the oxidized mixture. Data are presented which illustrate this and show that such an approach is unlikely to yield a completely satisfactory analytical method.

Thermogravimetric studies have been made on the solid solution and these have resulted in a method which can be applied to both super- and substoichiometric samples. The precision of this method corresponds to a standard deviation of 0.0014 in the oxygen-to-metal ratio. Data are presented on the thermogravimetric studies and on the method.

Variations in the cell parameter of the solid solution of the dioxides with the plutonium-to-uranium ratio and also the oxygen-to-metal ratio have been measured by $x$-ray diffraction techniques and these data are presented. The use of cell parameter measurements for stoichiometry determinations has been considered and its limitations are discussed.

The final results are in the shape of statistical information about the particles as an assembly, and not about individual particles. The method gives a semi-quantitative picuter of the particle size distribution and is applicable to loadings of up to $3 \mathrm{wt} \% \mathrm{Pu}^{239} \mathrm{O}_{2}$.

24

B. Cina, "Some Segregation Effects in Sintered $\mathrm{UO}_{2} \mathrm{PuO}_{2}$ Pellets," J. Nucl. Mat., 9 (1963)

111-113.

25

E. L. Zebroski, W. L. Lyon, and W. E. Baily, "Effect of Stoichiometry on the Properties of Mixed Oxide U-Pu Fuel," ANL-7120 (1966) 374-391.

26 S. K. Evans and W. L. Lyon, "An Electrical Probe for Checking Homogeneity in Mixed-Oxide Fuel Pellets," Trans. Am. Nucl. Soc., 10 (1967) 99-100.

27

J. L. Drummond and V. M. Sinclair, "Some

Aspects of the Measurement of the Oxygen to Metal

Ratio in Solid Solutions of Uranium and Plutonium

Dioxides," TID-7655 (1963). 
W. L. Lyon, "The Measurement of Oxygen to Metal Ratio in Solid Solutions of Uranium and Plutonium Dioxides," GEAP-4271 (1963).

A survey has been made of methods potentially usefulf or the determination of the oxygen to metal ratio in mixed oxides of uranium and plutonium. A gravimetric method was selected as being the most promising for adaption in a short period of time. Development of the technique has resulted in a reliable me thod which meets the requirements for unirradiated mixed oxide fuel samples. The method, based upon an equilibrium weight at $700^{\circ} \mathrm{C}$ in dry hydrogen, was shown to be capable of measurement of $\mathrm{O} /(\mathrm{Pu}+\mathrm{U})$ ratios in $20 \% \mathrm{PuO}_{2}$ $80 \% \mathrm{UO}_{2}$ pellets with a standard deviation of \pm 0.001 .

N. Mostin and G. Valenti, "Gravimetric Determination of the Oxygen Content of Uranium-Plutonium Mixed Oxides," EURAEC-818.

The present report describes a gravimetric method usable for the determination of the oxygen content in uranium-plutonium mixed oxides. It covers the following subjects:

A study, using a thermogravimetric balance, of the oxidation rates in air of uranium dioxide of different initial specific areas as well as the kinetics of reduction by hydrogen or carbon monoxide of $\mathrm{U}_{3} \mathrm{O}_{8}$ samples of various specific areas. From these measurements are deduced the time and the temperature needed to obtain stoichiometric oxides $\mathrm{UO}_{2.667}$, and $\mathrm{UO}_{2.000}$ or oxides of near-stoichiometric reproducible composition. In conclusion, standard working conditions are established for the routine determination of interstitial oxygen in uranium dioxide; air is used for oxidation, while reduction is performed preferably under hydrogen.

The behavior of $\mathrm{PuO}_{2}$ and $\mathrm{Pu}_{2} \mathrm{O}_{3}$ (or an intermediate composition) obtained from different salts heated in air, hydrogen or carbon monoxide. The lowest temperature needed to obtain plutonium dioxide of approximately stoichiome tric composition is $800^{\circ} \mathrm{C}$ for the heating conditions considered.

The determination of the interstitial oxygen content of plutonium-enriched uranium oxides. The experimental results show that, as in the case of uranium dioxide alone, the oxygen content can be determined with a reproducibility of \pm 0.004 stoichiometric units.

30

T. L. Markin and R. S. Street, "The UraniumPlutonium-Oxygen Ternary Phase Diagram," J. Inorg. Nucl. Chem., 29 (1967) 2265-2280.

The U-Pu-O phase diagram has been constructed between $\mathrm{UO}_{1.88}-\mathrm{U}_{3} \mathrm{O}_{8}$ and $\mathrm{PuO}_{2}-\mathrm{PuO}_{1,5}$ for all concentrations of $\mathrm{Pu}$ and between room temperature and $800^{\circ} \mathrm{C}$, from results obtained using a hightemperature $x$-ray powder diffraction camera, together with the results of other workers. The general formula of single-phase material is $\mathrm{U}_{1-\mathrm{z}} \mathrm{Pu}_{\mathrm{z}} \mathrm{O}_{2 \pm \mathrm{x}}$. Reduction of oxides having $\mathrm{z}>0.4$ to a sub-stoichiometric composition results in the formation, at room temperature, of two phases of composition $\mathrm{MO}_{2,0}$ and $\mathrm{MO}_{2-\mathrm{x}}$. Upon heating this two-phase product, a single phase is formed at a temperature dependent on the value of $z$. Reduction of oxides when $\mathrm{z}<0.4$ results in singlephase material at all temperatures. Partial oxidation when $\mathrm{z}<0.5$ results in either a single phase, fcc $\mathrm{MO}_{2+\mathrm{x}}$ or the $\mathrm{MO}_{2+\mathrm{x}}$ phase in equilibrium with an $\mathrm{M}_{4} \mathrm{O}_{9}$ type phase. Further oxidation causes the disappearance of the $\mathrm{MO}_{2+x}$ phase; the $\mathrm{M}_{4} \mathrm{O}_{9}$ type phase is then in equilibrium with a $\mathrm{M}_{3} \mathrm{O}_{8-y}$ phase.

31

T. L. Markin and E. J. McIver, "Thermodynamic and Phase Studies for Plutonium and UraniumPlutonium Oxides with Application to Compatibility Calculations," Plutonium 1965, Chapman and Hall, Lond on (1967) 845-857.

A high temperature $\mathrm{x}$-ray camera has been used to study the phase equilibria in the $\mathrm{PuO}$ and $\mathrm{U}-\mathrm{Pu}-\mathrm{O}$ systems and the results are reviewed briefly. A single phase non-stoichiometric fluorite type oxide exists over wide temperature and composition ranges for mixed uranium-platinum oxides containing between 10 and $30 \% \mathrm{Pu}$. Thermodynamic data has been obtained for $\mathrm{Pu}-\mathrm{O}$ and $\mathrm{U}-\mathrm{Pu}-\mathrm{O}$ at temperatures between $700^{\circ}$ and $1140^{\circ} \mathrm{C}$ using a high temperature galvanic cell employing solid electrolytes reversible to oxygen ions only. The measurements show that the oxygen potential changes very rapidly with composition as the stoichiometric composition is approached. The thermodynamic data for $\mathrm{PuO}_{2-\mathrm{x}}$ agrees with the suggested phase diagram and an extrapolation has been made from $700^{\circ} \mathrm{C}$ 
to room temperature that is consistent with the phase diagram. The thermodynamic data for the (U,Pu) oxides can be used to predict the composition attainable in various reducing gas mixtures at different temperatures and also the compatibility of the oxides with metals. Relevant values for the oxygen potential of oxide films on stainless steels are of use in such calculations.

32

L. E. Russel, et. al., "Observations on Phase Equilibria and Sintering Behavior in the $\mathrm{PuO}_{2}-\mathrm{UO}_{2}$ System,"' J. Nucl. Mat., 5 (1962) 216-227.

The phases present in $\mathrm{UO}_{2}$ and $\mathrm{PuO}_{2}$ mixed powder compacts of varying composition have been determined after sintering in hydrogen and argon, after argon-arc melting and after subsequent oxidation. Phase equilibria in the $\mathrm{Pu}-\mathrm{U}-\mathrm{O}$ system are discussed in terms of these findings.

The sintering behavior of the mechanically mixed oxide powders is found to vary appreciably with composition and sintering atmosphere.

33

N. H. Brett and L. E. Russell, "The Sintering Behavior and Stability of $(\mathrm{PuU}) \mathrm{O}_{2}$ Solid Solutions," Trans. Brit. Ceram. Soc., 62 (1963) 97-118.

The sintering behavior and stability in argon, carbon dioxide, and hydrogen at $1400^{\circ}$ and $1650^{\circ} \mathrm{C}$ of $(\mathrm{PuU}) \mathrm{O}_{2}$ solid solutions and the stability during arc-melting in argon have been studied. The solid solutions of ( $\mathrm{PuU}) \mathrm{O}_{2}$ were prepared by calcining coprecipitates of $\mathrm{Pu}(\mathrm{OH})_{4}$ and ammonium diuranate (A.D.U.). The calcination temperature which produced the maximum density in pellets sintered in hydrogen varied with composition from about $800^{\circ} \mathrm{C}$ for the $\mathrm{UO}_{2}-\mathrm{rich}$ powders to about $400^{\circ} \mathrm{C}$ for the $\mathrm{PuO}_{2}$-rich powders. Pellets prepared from $(\mathrm{PuU}) \mathrm{O}_{2}$ solid-solution powders generally sintered to a higher density in hydrogen than in argon or carbon dioxide and pellets of $10 \mathrm{~mol} \% \mathrm{PuO}_{2}$ had a higher density that those of $\mathrm{UO}_{2}$ or $20 \mathrm{~mol} \% \mathrm{PuO}_{2}$ sintered in a hydrogen atmosphere. Compositions in the range $0-20 \mathrm{~mol} \% \mathrm{PuO}_{2}$ remained single-phase during hydrogen sintering and arc-melting, but compositions containing $40 \mathrm{~mol} \%$ or more $\mathrm{PuO}_{2}$, on cooling were transformed into two-phase mixtures, probably $(\mathrm{PuU}) \mathrm{O}_{2}$ and $\mathrm{UO}_{2}-\mathrm{PuO}_{1.62}$ solid solutions. These observations are supported by $x$-ray powder diffractometric and metallographic examinations and by determinations of the $\mathrm{O} / \mathrm{Pu}+\mathrm{U}$ ratio.
34 C. Sari, U. Benedict and H. Blank, "Metallographic and $\mathrm{X}$-ray Investigations in the $\mathrm{Pu}-\mathrm{O}$ and $\mathrm{U}-\mathrm{Pu}-\mathrm{O}$ Systems," Thermodynamics of Nuclear Materials, 1967, IAEA, Vienna (1968) 587-611.

The $\mathrm{Pu}-\mathrm{O}$ system has been considered over the range $1.62<0 / \mathrm{Pu} \leq 2.00$ with specimens prepared at $1500-1600^{\circ} \mathrm{C}$ by reducing $\mathrm{PuO}_{2}$ pellets in hydrogen. The reduced samples were then quenched to room temperature and investigated by metallog- $p$ raphy and $x$-ray analysis. The results led to a modified $\mathrm{Pu}-\mathrm{O}$ phase diagram showing an extended field of the alpha-phase between $1.62<0 / \mathrm{Pu}$ $\$ 1.69$ instead of the formerly accepted compound at $\mathrm{O} / \mathrm{Pu}=1.61$ and a shift of the phase boundary for $\mathrm{PuO}_{2-\mathrm{x}}$ from $\mathrm{O} / \mathrm{Pu}=1.98$ to about 1.995 .

Published high temperature $\mathrm{x}$-ray and EMF data are consistent with the modified phase diagram. In the $\mathrm{U}-\mathrm{Pu}-\mathrm{O}$ ternary diagram the disproportionation reaction $\mathrm{MO}_{2}+>\mathrm{O}_{2}=\mathrm{MO}_{2+\mathrm{x}}+\mathrm{MO}_{2.66}$ established by

Brett and Fox at $750^{\circ} \mathrm{C}$ has been investigated at $600^{\circ}, 1000^{\circ}$, and $1400^{\circ} \mathrm{C}$ by metallography and $\mathrm{x}$-ray analysis. This reaction does not occur at $600^{\circ} \mathrm{C}$, but a metastable $\mathrm{M}_{3} \mathrm{O}_{7}$ phase is produced instead. An estimate on plutonium diffusion can be made on the bas is of the metallographic results. In the U-O system a modification of the phase diagram is proposed on the ground of a newly found orderdisorder transformation in $\mathrm{U}_{4} \mathrm{O}_{9}$ near $600^{\circ} \mathrm{C}$.

35

F. Thummler, R. Theisen and E. Patrassi, "Phase Relationships, Fabrication and Properties of SubStoichiometric Oxide Nuclear Fuel $\left[\mathrm{UO}_{2-\mathrm{x}}\right.$ and $\left(\mathrm{UPu}_{\mathrm{u}}\right)_{2-\mathrm{x}} \mathrm{]}$, ', EURFNR-286 (1967).

The concept of a sub-stoichiometric oxide nuclear fuel is discussed in the light of the publications and our own results. The constitution range of the $\mathrm{UO}_{2-\mathrm{x}}, \mathrm{PuO}_{2-\mathrm{x}}$ and $(\mathrm{UPu}) \mathrm{O}_{2}$ is dealt with first. Even at low temperatures there is no danger of a metallic $\mathrm{U}$ or $\mathrm{Pu}$ precipitation with the $\mathrm{Pu}$ contents which come into consideration for practical use. But this danger exists in the case of pure uranium dioxide. The problems posed by the fabrication of pellets and vibration powder from $(\mathrm{UPu}) \mathrm{O}_{2-x}$ seem technically soluble. Compatibility with clad materials is improved in the case of one-phase, i.e., metal-free - sub-stoichiometric products, as shown by a number of examples (some with $\mathrm{CeO}_{2}$ instead of $\mathrm{PuO}_{2}$ ). Heat conductivity is increased moderately, at least up to $1200-1500^{\circ} \mathrm{C}$. The improved heat conductivity is also apparent in the practical irradiation test. 
36

G. Berggren and R. S. Forsyth, "Some Studies of the High Temperature Behavior of $\mathrm{PuO}_{2}$ and $\mathrm{PuO}_{2}-\mathrm{UO}_{2}$ Mixtures," Plutonium 1965, Chapman and Hall, London (1967) 828-837.

The paper describes the results of experiments carried out on $\mathrm{PuO}_{2}$, and on $\mathrm{PuO}_{2}-\mathrm{UO}_{2}$ mixtures prepared by various preparative routes including physical mixing in the range $1-25 \% \mathrm{PuO}_{2}$. Observations have been made up to temperatures of about $1600^{\circ} \mathrm{C}$ by means of TGA, DTA and dilatometry, confirmatory work including density determinations and $\mathrm{X}$-ray and metallographic examination. Various gas atmospheres have been used.

Of particular interest are experiments in reducing atmos pheres for study of lower $\mathrm{O} /$ metal phases, and als o that stability of sintered pellets containing higher amounts of plutonium in oxidizing atmospheres.

37

G. Dean, "A Study of Plut onium Oxides and the ir Solubility in Uranium Dioxide," Plutonium 1965, Chapman and Hall, London, (1967) 806-827.

Results pertaining to the ternary system $\mathrm{U}-\mathrm{Pu}-\mathrm{O}$ are presented. The homogeneity ranges, corresponding to the vairious phases $\mathrm{MO}_{2 \pm \mathrm{X}}$, alpha$\mathrm{M}_{2} \mathrm{O}_{3}$ and beta- $\mathrm{M}_{2} \mathrm{O}_{3}$ phases exhibit a large homogeneity range; there is no MO compound.

38

M. H. Rand and T. L. Markin, "Some Thermodynamic Aspects of $(\mathrm{U}, \mathrm{Pu}) \mathrm{O}_{2}$ Solid Solutions and Their Use as Nuclear Fuels," Thermodynamics of Nuclear Materials, 1967, IAEA Vienna (1968) 637-650.

Data are now available for the free energies of formation of all the gaseous oxides of uranium and plutonium. Since the free energy data for the solid $(\mathrm{U}, \mathrm{Pu}) \mathrm{O}_{2 \pm y}$ can be derived from oxygen potential measurements, the pressure and composition of the vapor above these mixed oxides can be calculated. The results of such calculations are presented for a typical plutonium composition. An interesting aspect of this system is that since the oxygen potentials of the mixed oxides close to the $(\mathrm{U}, \mathrm{Pu}) \mathrm{O}_{2}$ composition are much higher than that of $\mathrm{UO}_{2}$, the predominant species over such oxides is initially $\mathrm{UO}_{3}(\mathrm{~g})$ rather than $\mathrm{UO}_{2}(\mathrm{~g})$. Since the uranium/plutonium ratios in the solid and vapor are not equal, when a mixed oxide is heated indefinitely in vacuo, both the $\mathrm{U} / \mathrm{Pu}$ and $\mathrm{O} /(\mathrm{U}+\mathrm{Pu})$ ratios change continuously. The results of iterative calculations for such cases are presented. Because of the poor thermal conductivity of the oxides, during operation there will be a temperature difference of nearly $1000^{\circ} \mathrm{C}$ between the outer surface and the center of the fuel pin. It is suggested that under normal irradiation conditions, the gradient of oxygen composition across the fuel will be determined by a constant $\mathrm{CO} / \mathrm{CO}_{2}$ or $\mathrm{H}_{2} / \mathrm{H}_{2} \mathrm{O}$ ratio in the gas phase (the gas permeating via cracks) rather than by a constant oxygen potential. Calculations are given for a typical temperature profile for a fuel clad with stainless steel. There is little effect for initially stoichiometric oxides but for both hypo- and hyper-stoichiometric material, the center of the fuel will become more non-stoichiometric than the outer surface. In addition, changes in the fissile material content may occur, particularly in hyperstoichiometric fuels, as a result of the large pressure gradients that will be set up. The possible effects of the variation in oxygen potential during a long irradiation are considered briefly.

39

W. L. Lyon and W. E. Baily, "The Solid-Liquid Phase Diagram for the $\mathrm{UO}_{2}-\mathrm{PuO}_{2}$ System," J. Nucl. Mat., 22 (1967) 332-339.

The liquidus and solidus were experimentally determined for the $\mathrm{UO}_{2} \mathrm{PuO}_{2}$ system by a thermal arrest method. The phase diagram is typical of a binary pair with complete solid solution and without maximum or minimum. A melting point of $2840 \pm 20^{\circ} \mathrm{C}$ was observed for $\mathrm{UO}_{2}$, and a melting point of $2390 \pm 20^{\circ} \mathrm{C}$ was observed for $\mathrm{PuO}_{2}$. Calculated the oretical liquidus and solidus curves exhibit remarkably good agreement with 40 the experimental values found.

J. K. Daws on and R. G. Sowden, Chemical Aspects of Nuclear Reactors, Butterw orth, London, 1963 162-171.

41

"Development and Testing of $\mathrm{PuO}_{2}-\mathrm{UO}_{2}$ Fast Reactor Fuels," NUMEC Progress Reports 3524-1 through 3524-39.

42

"Development of Plutonium Bearing Fuels," NUMEC Progress Reports 2389-1 through 2389-9.

43

"Development of Plutonium Bearing Fuels," NUMEC Progress Reports P-10 through P-106. 


\section{Appendix C: Plutonium Determination in Mixed Oxides by Calorimetric Measurements.}

The plutonium concentration $(\mathrm{g} / \mathrm{g})$ in the mixed oxides were calculated from the results of calorimetric measurements. The calorimeter is a twin isothermal microcalorimeter, described by Calvet and Prat. ${ }^{1}$ A large aluminum metal block provides the iosthermal environment. The two cells were made so that the ir thermal conductivities are nearly equal. Each cell has a manganin wire heater. A thermopile is used to detect temperature differences between the cells.

Radiometric calorimetry is unique in that the thermal output of a given radioactive nuclide is constant and continuous, and can be neither initiated nor terminated. Therefore, a steady-state method, described by Oetting, must be used. ${ }^{2}$ In this method one cell contains the radioactive heat source and the other cell contains an empty sample-holder. The empty, or dummy cell is electrically heated until the thermopile detects no temperature difference between the twin cells. At this point it is assumed that the power outputs of the two cells are equal. The current and voltage are used to calculate the power output of the dummy cell.
In order to calculate the plutonium concentration, the isotopic composition of the plutonium and the Americium-24l is subtracted from the measured power. The power output per gram of plutonium is then calculated using the isotopic and the specif power of each isotope. The plutonium concentration is found by dividing the corrected power by the power output per gram of plutonium and by the sample weight. The accuracy of determination is estimated to be $\pm 0.3 \%$ of the amount of plutonium present.

\section{REFERENCES}

1. E. Calvet and H. Prat, Recent Progress in Microcalorimetry, The MacMillan Company, New York (1963).

2. F. L. Oetting, "Average Beta Energy of Pu-24I by Calorimetry," Phys. Rev., 168 (1968) 13981401. 